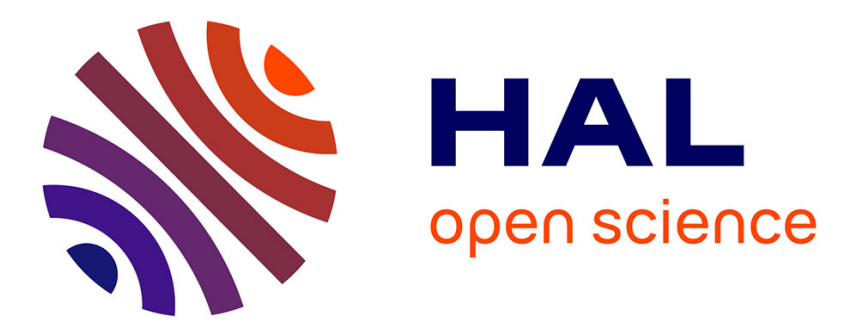

\title{
Predicting population viability of the narrow endemic Mediterranean plant Centaurea corymbosa under climate change
}

Asma Hadjou Belaid, Sandrine Maurice, Hélène Freville, David Carbonell, Eric Imbert

\section{To cite this version:}

Asma Hadjou Belaid, Sandrine Maurice, Hélène Freville, David Carbonell, Eric Imbert. Predicting population viability of the narrow endemic Mediterranean plant Centaurea corymbosa under climate change. Biological Conservation, 2018, 223, pp.19-33. 10.1016/j.biocon.2018.04.019 . hal-01801986

\section{HAL Id: hal-01801986 \\ https://hal.umontpellier.fr/hal-01801986}

Submitted on 28 May 2018

HAL is a multi-disciplinary open access archive for the deposit and dissemination of scientific research documents, whether they are published or not. The documents may come from teaching and research institutions in France or abroad, or from public or private research centers.
L'archive ouverte pluridisciplinaire HAL, est destinée au dépôt et à la diffusion de documents scientifiques de niveau recherche, publiés ou non, émanant des établissements d'enseignement et de recherche français ou étrangers, des laboratoires publics ou privés. 


\section{Title:}

Predicting population viability of the narrow endemic Mediterranean plant Centaurea corymbosa under climate change.

\section{Authors:}

Asma HADJOU BELAID ${ }^{a}$, Sandrine MAURICE ${ }^{a}$, Hélène FREVILLE ${ }^{b}$, David CARBONELL ${ }^{a}$, Eric IMBERTa,**

\section{Address:}

a ISEM-Université de Montpellier, CNRS, IRD, EPHE-Montpellier, France.

${ }^{\mathrm{b}}$ AGAP,Univ Montpellier, CIRAD, INRA, Montpellier SupAgro - Montpellier, France

*Corresponding author: Eric IMBERT, eric.imbert@umontpellier.fr 
1 Title:

2 Predicting population viability of the narrow endemic Mediterranean plant Centaurea corymbosa 3 under climate change.

\section{$5 \quad$ Abstract}

Climate change is a growing threat for global biodiversity, in particular for narrow endemic species. The Mediterranean region, which harbors an exceptional biodiversity, has been identified as one of the most sensitive regions to climate change. Based on a 22-year monitoring period, we analyzed the dynamic and viability of the six extant populations of a narrow endemic plant species of the Mediterranean area, Centaurea corymbosa, to predict their fate under two climatic scenarios. We constructed matrix projection models to calculate current asymptotic growth rates and to 2 perform stochastic projections including both demographic and environmental stochasticity. Neither 3 asymptotic growth rates nor their temporal variance were linked to population size and age at 4 flowering. Randomization tests showed that asymptotic growth rates were significantly different 5 among years but not among populations. An increase in temperature and a decrease in the number 6 of wet days had a negative impact on the whole life-cycle, particularly in the summer period, and 17 thus reduced asymptotic growth rates. Stochastic projections showed that an increased frequency of 8 extreme climatic events increased population extinction risk and decreased mean time to extinction. 9 The warm scenario had a more dramatic impact on population viability than the dry scenario. 20 Management recommendations are proposed to increase population viability of endangered plant 21 species such as C. corymbosa that face climate change.

\section{Keywords:}

23 Centaurea corymbosa; Climate change; Conservation; Extinction risk; Long-term survey; Matrix 24 projection models; Stochastic projections. 


\section{Introduction}

Ongoing climate change is expected to result in increase in drought and warm periods in several regions due to both an increasing frequency of extreme climatic events and long-term gradual changes (IPCC, 2007). Compared to some other taxonomic groups, plants are more vulnerable to climate change since they have relatively low migration capacity (Malcolm et al., 2006; Thomas et al., 2004). Gradual climate change and extreme events have already caused range shifts for some plant species (Chen et al., 2011), including range contraction with long-term population declines and extinctions (Lennartsson and Oostermeijer, 2001; Doak and Morris, 2010; Selwood et al., 2015, Wiens, 2016), or range expansion (Meer et al., 2016; Williams et al., 2015). This change is expected to become an even more important driver of global biodiversity loss over the next century (Heller and Zavaleta, 2009). Thus, population dynamics of many plant species are expected to be significantly affected by such changes (Breda et al., 2006; Meer et al., 2016; Nicolè et al., 2011; Ulrey et al. 2016). For conservation purposes, identifying climatic factors that impact population dynamics and predicting the consequences of climate change on species persistence have therefore become an important prerequisite to develop effective conservation strategies aimed at limiting population decline and extinction risk (Cotto et al., 2017; Malcolm et al., 2006; Thomas et al., 2004).

Climate change can either positively or negatively affect population dynamics (Lawson et al., 2015; Marrero-Gómez et al., 2007). For instance, climate change proved beneficial to populations of the widespread orchid species (Orchis purpurea) and is predicted to induce range expansion in the near future (Meer et al., 2016; Williams et al., 2015). In contrast, several studies have documented negative effects of summer temperature on growth rates for other plant species (Aragón-Gastélum et al., 2017; Riba et al., 2002; Shryock et al., 2014). In some cases, a given climatic variable has been shown to have diverging effects on separate vital rates within a species life-history (Csergő et al., 2017; Jolls et al., 2015; Nicolè et al., 2011; Peñuelas et al., 2004; Treurnicht et al., 2016). For example, a warm summer increased the flowering probability of Dracocephalum austriacum, whereas it decreased plant survival, leading to reduced effects of climate on population growth rates (Nicolè et al., 2011). Such opposite effects on population dynamics and demographic processes make it difficult to predict the net consequences of climate change on population viability (Meer et al., 2016; Nicolè et al., 2011). 
The Mediterranean region has been identified as one of the most sensitive regions to climate change (Ducrocq, 2016). Climate model projections indicate that warming and drying will likely continue (AllEnvi, 2016). At the end of the century (2080-2099 period), annual mean temperature is predicted to increase $\left(+3.5^{\circ} \mathrm{C}\right)$ with more extreme dry event frequency $(+46 \%)$ in this region (Christensen et al., 2007). Moreover, in most areas of the Mediterranean region, precipitation is predicted to decrease $(-12 \%)$, particularly in summer $(-24 \%$, Christensen et al., 2007). The Mediterranean region harbors an exceptional biodiversity, including a large number of rare and endemic plant species. Among them, 36\% are narrow endemics, i.e., they grow only in a single area or have a narrow geographic range (Thompson et al., 2005). Most of these species occur in rocky habitats, on steep slopes and in open vegetation with low species richness (Lavergne et al., 2004; Thompson et al., 2005). Such habitats are characterized by their stability both in relation to vegetation succession and human disturbance (Lavergne et al., 2005). Narrow endemic species are expected to be particularly sensitive to environmental shifts, as several of these species are extremely specialized and have evolved low dispersal ability (Isik, 2011; Lavergne et al., 2004, 2005; Thuiller et al., 2005).

Projection models that incorporate temporal environmental stochasticity are a powerful tool for predicting long-term population dynamics under climate change (Andrello et al., 2012; Crone et al., 2011, 2013; García et al., 2002). An increase in variability in vital rates due to climatic variations will usually decrease the long-term population growth (Morris et al., 2008). Thus, temporal variations may amplify population fluctuations and thus increase extinction risk, an effect being more pronounced for small populations (Isik et al., 2011; Lande et al., 2003; Morris and Doak, 2002). Species life-histories can however buffer the effects of climate variation. For instance, long duration of the life-cycle has been shown to decrease the impact of environmental stochasticity, making long-lived species facing climate change less prone to extinction (Morris et al., 2008). Demographic stochasticity can also be an important driver of population dynamics, whenever populations are of a small size (Lande et al., 2003). Such processes refer to chance events of individual survival and reproduction causing random variations in population growth rates (Caswell, 2001; Lande et al., 2003). These variations are expected to be more pronounced in small populations and thus lead to random fluctuations in population size that increase extinction risks (Lande et al., 2003; Zeigler, 2013). Including both environmental and demographic stochasticity in population viability analyses is thus crucial to forecast the fate of populations under climate change (Crone et al., 2011, 2013; Kaye and Pyke, 2003; Lande et al., 2003). 
Demographic studies investigating the long-term effect of climate change on narrow endemic Mediterranean plants remain rare. Such studies have mostly relied on short-term surveys, thus exploring limited year-to-year climatic variations (Crone et al., 2011) and consider only a subset of extant populations (e.g. Centaurea hyssopifolia; Matesanz et al., 2009, Brassica insularis; Noel et al., 2010, Ramonda myconi; Riba et al., 2002), making it difficult to predict species responses to climate change (Crone et al., 2011; Ehrlén et al., 2016). Long-term demographic surveys are needed to understand how past climatic variations have affected population dynamics, and to predict population viability under climate change (Andrello et al., 2012; Franklin et al., 2017; Hunter et al., 2010; Menges, 2000). Typically, at least 15-20 years of observations are necessary to predict population growth rate or extinction risk adequately (Zeigler, 2013). This is particularly true for perennial species, which may have a stage in their life-cycle that allows for species persistence under unfavorable conditions (Blume-Werry et al., 2016; Huelber et al., 2016; Morris et al., 2008).

Centaurea corymbosa is a narrow monocarpic short-lived species endemic to the Mediterranean region. The species grows in the Massif de la Clape in Southern France, on the top of cliffs and in nearby rocky areas of open vegetation (Colas et al., 1997). Only six populations are known, which have been surveyed since June 1994 using permanent plots. In this paper, we used this unique demographic dataset collected during a 22-year period (totaling 6112 individual lifehistories) to predict species dynamics under different climate scenarios. To do so, using matrix population models, we estimated asymptotic growth rates and vital rates for each population and each pair-of-years over the 22-year period. First, we tested for spatial and temporal variations in population dynamics and also tested whether small populations had lower asymptotic growth rate and showed higher variance in asymptotic growth rate than large populations. In addition, we tested whether age at flowering could buffer the effects of environmental stochasticity. Next, we assessed the relationship of climatic variables with demographic parameters over the 22-year period. More specifically, we tested whether any climatic situation contributing to drought negatively affected asymptotic growth rates and vital rates, since water availability is essential for the establishment of newly recruited plants and the survival of vegetative plants. Moreover, because flowering is closely linked with size and thus with plant growth in monocarpic plants (Meer et al., 2016; Metcalf et al., 2003; Williams et al., 2015), we tested whether probability of flowering depended on climatic conditions prevailing only the months before flowering or varied according to a cumulative multiyear climate effect. Finally, by incorporating both environmental and demographic stochasticity, we simulated the fate of populations under two climatic scenarios, a warm scenario reflecting an increase in the frequency of hot years, and a dry scenario corresponding to an increase in the 
120 frequency of drought events, and thus tested which of the two scenarios would have the largest 121 impact on population persistence.

122 2. Materials \& Methods

\subsection{Biological model, demographic and climatic datasets}

\subsubsection{Study species}

125

126

127

128

129

130

131

132

133

134

135

136

137

138

139

140

141

142

143

Centaurea corymbosa Pourret (Asteraceae) is a narrow Mediterranean species endemic to the Massif de la Clape near Narbonne (southern France, $43^{\circ} 13$ N, $3^{\circ} 08$ E). It is listed in the French Red Book of endangered species and in the European Habitat Directive list of priority species, thus precise coordinates of the populations are not given. C. corymbosa has been extensively studied since 1994 and several papers have already reported on its ecological characteristics (Colas et al., 1996; Imbert, 2006; Imbert et al., 2012; Kirchner et al., 2005), population dynamics (Fréville et al., 2004; Kirchner et al., 2006) and population genetics (Colas et al., 1997, 2001; Fréville et al., 2001; Fréville et al., 1998; Hardy et al., 2004; Riba et al., 2005). Here, we only summarize the most important features and results related to the current study. C. corymbosa is restricted to a $3-\mathrm{km}^{2}$ area and is known from only six populations found on different cliffs $0.3-2.3 \mathrm{~km}$ apart (mean elevation $132 \mathrm{~m}, \mathrm{SD}=37.4, \mathrm{n}=41$ permanent plots, see below). Individuals grow on the top of cliffs and in rocky areas. These populations are currently not directly threatened by human activities. However, habitat closure due to the abandonment of grazing contributes to the isolation of open and suitable habitats, and thus increased fragmentation among patches. The species has a monocarpic perennial life-cycle. Individuals stay as a rosette for 2 to 13 years before flowering. The flowering period extends from May to mid-August, and most of the seeds germinate between September and December. Seeds are dispersed over short distances by wind and ants. Despite suitable habitats in the vicinity of the six populations, it has been shown that $C$. corymbosa is very unlikely to colonize new sites (Colas et al., 1997; Olivieri et al., 2016; Riba et al., 2005).

\subsubsection{Demographic dataset}

Data have been collected since June 1994 in the six populations. However, in the first census, the status of non-flowering plants (seedling or rosette) could not be assessed. Thus, matrix population models were based on 22 years of demographic survey (1995-2016), except for one population (Portes, 1996-2016). Data collection is described in details in Fréville et al. (2004). Every 3 months (June, September, December and March), we recorded the presence and the status 
150 of each individual within 41 permanent plots and new seedlings were added to the datasets (see Appendix A1). During the flowering period (mid-June), we also surveyed the whole distribution area of the species to count the total number of flowering plants per population (exhaustive count, Table 1 and Appendix A2). A total of 6112 individual life-histories were used to construct population projection models (Table 1 and Appendix A1).

155

156

157

158

159

160

161

162

163

164

165

166

167

168

169

170

171

172

173

\subsubsection{Climatic dataset}

Climatic data were obtained from the closest meteorological station located at INRA Pech Rouge $\left(43^{\circ} 1444 \mathrm{~N}, 3^{\circ} 1338 \mathrm{E}\right.$, elevation $\left.=40 \mathrm{~m}\right)$ less than $5 \mathrm{~km}$ from the populations of $C$. corymbosa. We used daily mean temperature, daily minimum and maximum temperatures and daily precipitation. Over the 22 years of this study, the Massif de la Clape experienced a classical warm Mediterranean climate (average mean temperature $15.1 \pm 0.6{ }^{\circ} \mathrm{C}$ from June $t$ to May $t+1$, Fig. 1) with a warm summer period. Precipitation regime was also characteristic of the Mediterranean climate with an average of $540.8 \mathrm{~mm}$ per year from June $t$ to May $t+1$ with large inter-annual variation ( $\mathrm{SD}=175.46$, Fig. 1$)$. The number of days with precipitation $>1 \mathrm{~mm}$ ranged from 35 days to 68 days with an average of 48.5 days per pair-of-years ( $\mathrm{SD}=8.9$, Fig. 1).

\subsection{Deterministic analyses}

\subsubsection{Matrix projection models}

As described in Fréville et al. (2004), the life-cycle is based on a prebreeding census performed before the germination pulse, with a one-year interval from June $t$ to May $t+1$. Three stages were defined: seedlings (individuals less than 1 year old), rosettes (vegetative plants older than 1 year), and flowering plants. We estimated lower-level vital rates (survival $s_{i}$, flowering probability $\alpha_{i}$ conditional to survival and fecundity $f$ ) to construct a stage structured Matrix Projection Model (MPM). For each population and each pair-of-years, the projection matrix representing the life-cycle is given by:

$$
A=\left(\begin{array}{ccc}
0 & 0 & f_{s_{0}} \\
s_{1}\left(1-\alpha_{1}\right) & s_{2}\left(1-\alpha_{2}\right) & s_{3}\left(1-\alpha_{3}\right) \\
s_{1} \alpha_{1} & s_{2} \alpha_{2} & s_{3} \alpha_{3}
\end{array}\right)
$$

From the 22 years of demographic survey, we constructed 21 matrices per population (see appendix B for projection matrices per population). The probabilities of a flowering plant to survive $\left(s_{3}\right)$ and to reproduce the year after $\left(\alpha_{3}\right)$ were very low, in agreement with the monocarpy of the 
species, and had negligible effects on population dynamics (see appendix B). Using a deterministic MPM (linear, time-invariant), we calculated the asymptotic growth rate $\lambda_{a}$ as the dominant eigenvalue of the matrix A of the corresponding pair-of-years. The model did not include seed bank and migration. Indeed, less than $5 \%$ of seeds may remain dormant for one year and seed dispersal among populations is highly limited (Colas et al., 1997; Fréville et al., 2004; Imbert, 2006). The net fecundity $f_{s_{0}}$ was estimated as the ratio of the number of seedlings observed in June of a given year over the number of flowering plants observed within permanent plots in June of the previous year. Our three-month survey made it possible to decompose the net fecundity $f_{s_{0}}$ into a fecundity term $f$ (number of just-emerged seedlings assessed every three months over number of flowering plants in June $t-1$ ) and survival of just-emerged seedlings $s_{0}$ (number of seedlings observed in June $t$ over total number of just-emerged seedlings observed from June $t-1$ to May $t$, Colas et al., 2008; Fréville et al., 2004). We obtained four null values in asymptotic growth rates (three for Cruzade and one for Peyral), which corresponded to years with no flowering plant within plots and null values in rosette survival $s_{2}$. In such case, the persistence of the plot depended on new rosettes coming from the seedling stage ( $s_{1}$ never equaled zero), and seed dispersal from the closest flowering plants outside plots. When calculating the geometric mean of asymptotic growth rates over years for each population, we excluded these null values.

\subsubsection{Patterns of spatio-temporal variations in asymptotic growth rates}

To test for temporal and spatial variation in asymptotic growth rates, we used nonparametric randomisation tests (Caswell, 2001). Temporal variation was tested by randomly permuting individual life-histories (status at $t$ and fate at $t+1$ ) among pair-of-years when considering all data as a single population. For spatial variation, we permuted the whole individual life-history (from germination to death) between populations (see Fréville et al., 2004). Each lifehistory appeared exactly once in each randomized dataset, maintaining the original sample sizes. For each set of permuted data, we calculated asymptotic growth rate for each group (year or population) and then computed the standard deviation of $\lambda_{a}$ between groups. The probability that $\sigma\left(\lambda_{a}\right) \geq \sigma_{o b s}$ under the null hypothesis $H_{0}$ (no group effect) was computed based on 2000 random permutations. We rejected $H_{0}$ when this probability was smaller than 0.05 (Caswell, 2001). We used linear models to test for the effect of population size on asymptotic growth rates and their temporal variance, using the total number of flowering plants obtained by the exhaustive survey as a proxy of population size (Table 1). We used also a linear model to test for the effect of mean age at flowering (Table 1) on the variance in population growth rate. 


\subsubsection{Retrospective and prospective analyses}

We performed a life-table response analysis (LTRE) with a random design to assess how lower-level vital rates contributed to the variance in asymptotic growth rates $\operatorname{var}\left(\lambda_{\mathrm{a}}\right)$ observed among years. This analysis was performed on the pooled data over populations, provided that we did not detect significant spatial variation in population growth rates. The decomposition of $\operatorname{var}\left(\lambda_{\mathrm{a}}\right)$ in term of lower-level vital rates $p$ is expressed as:

$$
\operatorname{var}\left(\lambda_{a}\right) \approx \sum_{i, j} \operatorname{cov}\left(p_{i}, p_{j}\right) \frac{\partial \lambda_{a} \partial \lambda_{a}}{\partial p_{i} \partial p_{j}}
$$

where $\operatorname{cov}\left(p_{i}, p_{j}\right)$ is the covariance of $p_{i}$ and $p_{j}$ (Caswell, 2001). A prospective analysis was also conducted to assess the population dynamic response to changes in lower-level vital rates. We calculated the elasticity of $\lambda_{a}$ to lower-level vital rates $p$ as:

$$
e=\frac{p \partial \lambda_{a}}{\lambda_{a} \partial p}
$$

\subsection{Relationships between demographic parameters and climate}

From the raw climatic dataset, we extracted seven relevant variables assumed to have an influence on demographic parameters, given the existing literature (Fréville et al., 2004; Riba et al., 2002) and our knowledge of Mediterranean plant species. We thus calculated the average of daily mean temperature and daily maximum temperature, the number of days with mean $\mathrm{T}^{\circ}>25^{\circ} \mathrm{C}$ (corresponding to mean $+\mathrm{SD}$ ) and the number of freezing days (minimum $\mathrm{T}^{\circ}<0^{\circ} \mathrm{C}$ ). In addition, we calculated both the average cumulative precipitation and the number of days with precipitation $>$ $1 \mathrm{~mm}$ that hereafter will be referred as the number of wet days. We also calculated the number of days with precipitation $>20 \mathrm{~mm}$. This threshold value was equal to mean $+\mathrm{SD}$. We thus considered this variable as reflecting the number of heavy precipitation events in the Massif de la Clape.

We tested for the effect of climate on demographic parameters using generalized linear models with identity link for asymptotic growth rates and fecundity $f$ (both log-transformed), and logit link for survival and flowering probabilities with the binomial distribution. First, we tested for relationships between annual averages of each climatic variable calculated from June $t$ to May $t+1$ and asymptotic growth rates $\lambda_{a}$, and also tested for quadratic effects and multiyear cumulative effect with a time lag of one year of each climatic variable (Appendix E.1). We then tested for the effect of the variables that we found significant in the single-variable GLMs, using a forward stepwise 
selection approach. Starting from the null model, we added at each step the variable having the highest $\mathrm{R}^{2}$ value in the single-variable models (Appendix E.1). For logistic models, we used $\mathrm{R}_{\mathrm{LR}}^{2}$, the pseudo-coefficient of determination based on the likelihood-ratio test and given by $\mathrm{R}_{\mathrm{LR}}^{2}=1$ $\left(\mathrm{L}_{\text {null }} / \mathrm{L}_{\text {full }}\right)^{2 / n}$ where $\mathrm{L}_{\text {null }}$ and $\mathrm{L}_{\text {full }}$ are the likelihoods of the null and the fitted models, respectively (Shinichi Nakagawa et al., 2013). The significance of each added variable in the model was tested using an analysis of deviance (Appendix E.2). From the best model, we reported the estimated coefficient $(\beta)$ and its significance for each variable in the model after scaling climatic variables. Second, to understand biological processes at a finer scale, we tested for the impact of the seasonal climate on lower-level vital rates by considering only climatic variables that significantly impacted asymptotic growth rates, using the same approach as described above. We included the seasonality effect in GLMs by averaging variables over three-month periods separating two successive censuses (Appendix E.3). GLMs were fitted using R Stats-package (version 3.3.1). The $\mathrm{R}_{\mathrm{LR}}^{2}$ was calculated using the R-command 'r.squaredLR' from the MuMIn-package (version 1.15.6).

\subsection{Stochastic projections under climate change}

Based on the IPCC Fourth Assessment Report, the frequency of extreme warm and dry events is expected to increase (Christensen et al., 2007). We thus built stochastic matrix models to simulate the fate of $C$. corymbosa populations under two scenarios of climatic variations, representing an increased frequency of extreme events either for temperature or precipitation (Bucharovà et al., 2012; Shryock et al., 2014). To simulate the fate of populations, we incorporated environmental stochasticity by drawing an entire matrix at each time step (sampling with replacement) among the 21 available matrices (Crone et al., 2011, 2013; Kaye and Pyke, 2003). Because $C$. corymbosa has small population sizes, we also incorporated demographic stochasticity in the models. Such stochasticity is due to the independent chance of transition and reproduction among individuals (Engen et al., 1998; Lande, 1993; Melbourne and Hasting, 2008). From the existing individuals at year $t$, we drew the number of individuals making each transition from stage $j$ to stage $i$ including death at each time step in a multinomial distribution characterized by the $\mathrm{a}_{\mathrm{ij}}$ transition probabilities of the matrix that we randomly drew (Andrieu et al., 2017; Caswell, 2001; Melbourne and Hasting, 2008; Morris and Doak, 2002). The number of recruited seedlings was drawn in a Poisson distribution with mean equal to the $f_{s_{0}}$ value of the drawn matrix. In the case of C. corymbosa, demographic stochasticity indeed increased fluctuations in population size over time and thus increased extinction risk (see Appendix F), in agreement with both theoretical studies (e.g. Engen et al., 2005; Lande, 1993; Lande, 2003) and empirical ones (e.g. Fujiwara and Caswell, 2001; 
Melbourne and Hasting, 2008; Jepsonn and Forslund, 2012). Therefore, we combined both demographic and environmental stochasticity to simulate the fate of populations under climate scenarios.

The initial population size $N_{0}$ used to start our simulations was calculated from the stable stage distribution obtained from the arithmetic mean of the total number of flowering plants recorded in the population (exhaustive survey) from 2010 to 2016, and the scaled eigenvector $W$ from the arithmetic mean matrix over years (2010-2016) when pooling data over populations. $N_{0}$ is given by $N_{0}=W \frac{N f r}{w_{3}}$ where $w_{3}$, the third element of the scaled eigenvector, represents the proportion of the number of flowering plants. We simulated population dynamics using 1000 stochastic iterations, each iteration representing a trajectory of population size over 100 years. For a given trajectory we calculated the growth rate $\lambda_{j}$ as:

$$
\lambda_{j}=\exp \left[\frac{\ln \left(n_{j}(T)\right)-\ln \left(n_{j}(0)\right)}{T}\right]
$$

where $n_{j}(T)$ and $n_{j}(0)$ were the population size of the $j^{\text {th }}$ trajectory at $t=T$ and $t=0$, respectively, and $T$ being the last year at which population size was non-null. The stochastic growth rate $\lambda_{s}$ was obtained as the median of $\lambda_{j}$ over 1000 trajectories. Extinction probability at a given time $t$ corresponds to the number of trajectories for which $N(t)=0$ over the total number of trajectories; we calculated extinction probability at $t=50$ years $\left(\mathrm{P}_{50}\right), t=100$ years $\left(\mathrm{P}_{100}\right)$ and the mean time to extinction $\left(\mathrm{T}_{\text {ext }}\right)$ based on 100 trajectories over 100 years. We carried out 1000 such simulations, each of 100 trajectories, to obtain a sampling distribution of $\mathrm{P}_{50}, \mathrm{P}_{100}$ and $\mathrm{T}_{\text {ext }}$. We calculated mean value of those parameters over the 1000 simulations and $95 \%$ confidence intervals by taking the $2.5^{\text {th }}$ and the $97.5^{\text {th }}$ percentile of the simulated distribution (Shryock et al., 2014). All stochastic analyses were implemented using the R popbio-package, version 2.4.3 (Stubben and Milligan, 2007).

Climatic scenarios were first simulated by increasing the frequency of drawing matrices corresponding to extreme warm and extreme dry years (Andrello et al. 2012; Hunter et al., 2010; Shryock et al., 2014) from the observed frequency over the 22-year period $\mathrm{q}^{*}$ to $\mathrm{q}=0.8$, that represent, respectively, the warm and the dry scenario. Based on the results of the GLM analyses testing for the effects of climatic variables on asymptotic growth rates, we used the daily mean temperature and the number of wet days to characterize warm and dry scenarios, respectively. 
Following Williams et al. (2015), extreme years corresponded to years with climate values larger than one standard deviation above the daily mean for temperature and lower than one standard deviation below the mean for precipitation. In the warm scenario, warm years were represented by pair-of-years with high daily mean temperature (2006-2007, 2013-2014, 2014-2015 and 2015-2016, Fig. $\left.1, q^{*}=4 / 21=0.19\right)$. In the dry scenario, dry years were represented by pair-of-years with low numbers of wet days (2001-2002, 2006-2007 and 2010-2011, Fig. 1, q*=3/21=0.14).

Second, following the approach described in Salguero-Gomez et al. (2012), we focused on a particular climate scenario resulting from the Regional Climate Model (RCM) proposed by the Euro-Cordex 2014 project (Jacob et al., 2014). We used the RCP4.5 scenario representing an intermediate scenario of increasing $\mathrm{CO}_{2}$ concentration until 2060. The regional climate model simulations provided predicted values of daily precipitation and mean temperature. We then extracted these data for the closest geographic location, which is less than $1 \mathrm{~km}$ apart from the centroid of the species distribution $(43.13710 \mathrm{~N}, 3.07327 \mathrm{E})$ and less than $6 \mathrm{~km}$ apart from the meteorological station we used to get observed climatic data. Overestimation of precipitation in RCMs is a well-known problem, in particular in areas close to the Mediterranean Sea (Gao et al., 2008; Ruffault et al., 2014). Therefore, to estimate the frequency of extreme years in the future (2020-2099), we used threshold values from the back-projected model values (Salguero-Gomez et al., 2012). Using the back-projected data from the reference period (1971-2005), we defined warm years as those with mean temperature from May $t$ to June $t+1$ greater than $14.5+1.23$ (mean $+\mathrm{SD}$ ) and dry years as those with number of wet days lower than 68.6 - 14.8 (mean - SD). Comparing the observed data and the back-projected data for the overlapping period 1995-2005, we indeed document an overestimation of the number of wet days predicted by the regional model compared to the observed one (paired $t$-test $=4.57, \mathrm{df}=8, \mathrm{p}<0.002$ ). In contrast, predicted and observed daily mean temperatures and total precipitation were not significantly different $(p>0.10)$. Simulated data are available on the Drias platform (www.drias-climat.fr).

\section{Results}

\subsection{Patterns of spatio-temporal variations in asymptotic growth rates}

Asymptotic growth rates $\lambda_{a}$ calculated per population and per pair-of-years showed a decreasing trend over time $(\beta=-0.01, p=0.02$, Fig. $2 \mathrm{~A})$. The slope of the trend for each population separately was significant only for the smallest population (Cruzade: $\beta=-0.04 ; p=0.01$, Fig. 2D). When pooling populations within each pair-of-years, the geometric mean of asymptotic growth 
rates over years was 0.880 (Table 1), with $\lambda_{a}$ ranging from 0.432 (2006-2007) to 1.815 (2012-2013). Geometric means of $\lambda_{a}$ over years per population were all lower than 1 and varied between 0.710 (Peyral) and 0.836 (Enferret1, Table 1). No significant relationship was detected between asymptotic growth rate and population size $(\beta=0.0003 ; \mathrm{p}=0.46)$. Randomization tests showed that the difference in $\lambda_{a}$ among years was highly significant $(\mathrm{p}<0.001$, see appendix $\mathrm{C})$. In contrast, asymptotic growth rates $\lambda_{a}$ were not significantly different among populations $(\mathrm{p}=0.16$, see appendix $\mathrm{C}$ ). The variance in $\lambda_{a}$ per population was not significantly correlated with mean age at flowering $(\beta=-0.02 ; p=0.68)$ nor with population size $(\beta=0.0003 ; p=0.55)$.

\subsection{Retrospective and prospective analyses}

As $\lambda_{a}$ did not differ significantly among populations, retrospective and prospective analyses were performed after pooling individuals across populations. The observed variance in asymptotic growth rates among years was equal to 0.083 , and was mainly explained by the variation in both the fecundity term $(f)$, the survival of seedlings $\left(s_{1}\right)$ and the survival of rosettes $\left(s_{2}\right)$ having the highest contributions $(0.025,0.023$ and 0.021 , respectively, Fig. 3), followed by the survival of justemerged seedling $\left(s_{0}\right)$ and the flowering probability of rosettes $\left(\alpha_{2}\right)$ having a similar contribution (0.008, Fig. 3). Rare events in the life-cycle (flowering probabilities $\alpha_{1}$ and $\alpha_{3}$, and survival of flowering plants $s_{3}$ ) had negligible contributions (sum to 0.0009, Fig. 3 and appendix D). The largest elasticity of asymptotic growth rate was associated with rosette survival $\left(s_{2}\right)$ followed by the fecundity term $f$ (mean number of just-emerged seedlings per flowering plant), the survival of justemerged seedling $\left(s_{0}\right)$, seedling survival $\left(s_{1}\right)$ and the flowering probability of rosettes $\left(\alpha_{2}\right.$, Fig. 3). Elasticity of $\lambda_{a}$ to the remaining lower-level vital rates representing rare events $\left(s_{3}, \alpha_{1}\right.$ and $\left.\alpha_{3}\right)$ summed only to $1 \%$ (Fig. 3). These latter rates were thus not considered for the GLMs investigating the relationship between lower-level vital rates and climatic variables.

\subsection{Relationship between asymptotic growth rates and climate}

Asymptotic growth rate, when pooling populations, was best explained by a model including only two climatic variables $\left(\mathrm{R}^{2}=0.58\right.$, Appendix E.2), with a high positive effect of the annual number of wet days $(\beta=0.15, \mathrm{p}=0.004)$ and a negative effect of the annual average daily mean temperature $(\beta=-0.11, p=0.03)$. The number of freezing days, the cumulative precipitation and the number of days with precipitation $>20 \mathrm{~mm}$ proved non-significant ( $\mathrm{p}>0.05$, Appendix E.1). No multiyear cumulative effect and no quadratic effect of climatic variables were significant $(\mathrm{p}>$ 0.05, Appendices E.1). 
359

360

361

362

363

364

365

366

367

368

369

370

371

372

373

374

375

376

377

378

379

380

381

382

383

384

385

386

387

388

Overall, warming and drought negatively affected vital rates. The mean number of justemerged seedlings per flowering plants $f$ was negatively impacted by the daily mean temperature during both summer and fall periods (Table 2). The survival of just-emerged seedlings $s_{0}$ was positively impacted by the number of wet days during the germination period (both fall and the winter periods), and negatively impacted by the daily mean temperature during both summer and fall periods (Table 2). Seedling survival $s_{1}$ was negatively affected by an increase in the daily mean temperature during the summer and fall periods, and positively affected by an increase in the number of wet days during the same periods (Table 2). Rosette survival $s_{2}$ decreased with increasing summer daily mean temperature (Table 2). Finally, the flowering probability of rosettes $\alpha_{2}$ was negatively impacted by the summer daily mean temperature and positively impacted by the number of wet days during the fall period (Table 2).

\subsection{Stochastic projections under climate change}

In absence of climate change, when randomly drawing each matrix with equal probability $(1 / 21)$, stochastic growth rates $\lambda_{s}$ were significantly lower than 1 when pooling populations $\left(\lambda_{s}=\right.$ $0.881, C I=[0.877,0.889]$, Table 1). Stochastic growth rates were also lower than 1 in each population, ranging from 0.742 for the smallest population Cruzade $(C I=[0.732,0.770])$ to 0.836 for the largest one Enferret2 ( $C I=[0.829,0.851]$, Table 1).

To assess the combined effect of environmental and demographic stochasticity on population viability, we compared the fate of the smallest population Cruzade and the largest one Enferret2, using their respective population size at $t=0$ (see details above and Fig. 4). As we did not detect any significant variation in asymptotic growth rates among populations, we pooled data across population for each pair-of-years to obtain the 21 matrices used to simulate climate change. In the warm scenario, when increasing the frequency of extreme years from q* $(4 / 21=0.19)$ to 0.8 , stochastic growth rates decreased from 0.882 to 0.761 for the largest population (Enferret2, Fig. 4A) and from 0.879 to 0.765 for the smallest one (Cruzade, Fig. 4C). Under the RCP4.5 scenario, the predicted frequency of warm year $\mathrm{q}_{\text {pred }}$ characterized by a daily mean temperature $>15.63{ }^{\circ} \mathrm{C}$ for the period 2020-2099 equaled 0.78 and led to the extinction of both populations at 100 years in most simulations (Figs. 4A and 4C, solid black lines). Comparing this scenario with those of no climate change (Figs. 4A and $4 \mathrm{C}$, dashed green lines), extinction probability at 50 years $\left(\mathrm{P}_{50}\right)$ increased from 0.37 to 0.99 for Enferret2 and from 0.82 to 0.99 for Cruzade, while extinction 
probabilities at 100 years $\left(\mathrm{P}_{100}\right)$ were close or equal to 1 for both populations. The mean time to extinction decreased from 57 to 26.4 years for Enferret2, and from 32 to 16 for Cruzade.

The dry scenario had less dramatic consequences on the viability of populations than the warm scenario (Fig. 4B and 4D). The increase in dry year frequency from $\mathrm{q}^{*}(3 / 21=0.14)$ to 0.8 led to a small reduction in $\lambda_{s}$ from 0.882 to 0.855 for Enferret2 and from 0.879 to 0.851 for Cruzade (Figs. 4B and 4D, respectively). The RCP4.5 scenario predicted a frequency of dry years $\mathrm{q}_{\text {pred, }}$, corresponding to a number of wet days lower than 53.8 days, equaled to 0.15 , a value very close to the one observed during the 22-year period of our demographic survey. The RCP4.5 scenario did not result in any significant change in extinction probabilities and mean time to extinction compared to the scenario of no climate change, whatever the size of populations (Figs. 4B and 4D, solid black lines).

\section{Discussion}

\subsection{Long term population dynamics of Centaurea corymbosa}

Our results demonstrate the need for long-term demographic surveys to better understand the spatio-temporal demographic variability on plants (Blume-Werry et al., 2016; Compagnoni et al., 2016; Crone et al., 2011; Huelber et al., 2016). Indeed, our study based on 22 years of data provided a more accurate picture of the determinants of population dynamics in C. corymbosa than the study of Fréville et al. (2004) based on 8 years of data. In Fréville et al. (2004), the standard deviation in asymptotic growth rates $\sigma(\lambda)$ was 0.116 among years and 0.099 among populations, with significant differences among years and populations. In the current study, variation among populations became non-significant and temporal variation in asymptotic growth rates was rather synchronized among populations (Fig. 2). This pattern is not surprising given the narrow distribution of $C$. corymbosa and is largely consistent with studies of other narrowly distributed species (Buckley et al., 2010; Kiviniemi and Löfgren, 2009; Ramula et al., 2008). More importantly, the standard deviation $\sigma(\lambda)$ observed over the 22-year period was much larger $(0.230)$ than the one (0.116) reported in Fréville et al. (2004). In agreement with the results of the permutation tests, we did not find any significant correlation between population dynamics and population size. Indeed, we did not find any evidence that small populations had lower population growth rates. Moreover, the variance in asymptotic growth rates among years did not increase with decreasing population size. In contrast to other demographic studies (Lande et al., 2003; Zeigler, 2013), we thus did not find any evidence of a greater sensitivity of the smallest populations to both environmental and 
demographic stochasticity in our species. In addition, the variance in asymptotic growth rate was not correlated with mean age at flowering per population. We thus did not find evidence for demographic buffering in populations with greater longevity, in contrast to what has been found at an inter-specific scale in Morris et al. (2008). Population dynamics of C. corymbosa is thus mainly affected by environmental factors that vary over time rather than by spatial factors.

Average and most of the yearly asymptotic growth rates were lower than 1 for each population and when pooling individuals across populations. Overall, we observed a declining trend in yearly asymptotic growth rates over the 22-year period (Fig. 2), this trend being significant for the smallest population and when considering all populations (Figs. 2A and 2D, respectively). Asymptotic growth rates were negatively impacted by an increase in temperature and positively impacted by the number of wet days. Consistent with these results, asymptotic growth rates attained extreme values in years corresponding to extreme climatic events. Indeed, when pooling all individuals in a single population, the lowest value (0.432, Fig. 2A) was observed in 2006-2007 when the mean temperature was the highest $\left(16.3^{\circ} \mathrm{C}\right.$, Fig. 1) and the number of wet days was the lowest (34 days, Fig. 1). The highest growth rate (1.815, Fig. 2A) corresponded to 2012-2013, when we observed the second lowest mean temperature $\left(14.2^{\circ} \mathrm{C}\right.$, Fig. 1$)$ and the highest number of wet days (66 days, Fig. 1). Thus, population dynamics of $C$. corymbosa was mainly affected by extreme climatic events, which are predicted to increase in the future. Climatic variables investigated here did not show any marked temporal trend over the 22-year period of our demographic survey (Fig.1), which could explain the weak temporal trend observed in asymptotic growth rates. Overall, our study confirms that extreme climatic events are an important driver of plant population dynamics as reported in other studies (Andrello et al., 2012; Davison et al., 2010; McDowell et al., 2008; Shryock et al., 2014; Ulrey et al., 2016).

In contrast to some studies reporting both negative and positive effects of climate change on vital rates (Meer et al., 2016; Meisner et al., 2014; Nicolè et al., 2011), our study documents a consistent negative effect of increased temperature and drought on lower-level vital rates in $C$. corymbosa. Regarding temperature, the most critical season that impacted lower-level vital rates was the summer period, since increasing summer daily mean temperature negatively affected both fecundity, survival probability and flowering probability. In contrast to our study, flowering probability was found to be positively impacted by high temperature in some temperate plant species (e.g. Himantoglossum hircinum, Meer et al., 2016; Dracocephalum austriacum, Nicolè et al., 2011). While a negative effect of increasing temperature on flowering probability was also 
reported in Peñuelas et al. (2004), this pattern was only observed in the southern Mediterranean sites but not in the northern ones. A likely explanation of this negative effect is that warm summers increase evapo-transpiration and decrease soil moisture (Christensen et al., 2004; Peñuelas et al., 2004). This could lead to a decrease in plant biomass as a consequence of rosette shrinking that in turn reduces the amount of resources that a plant can allocate to reproduction (Manders and Smith, 1992). This is particularly true for monocarpic perennial species, where flowering probability has been shown to increase with plant size (Metcalf et al., 2003). Regarding precipitation, the youngest plants were the most impacted by the number of wet days. This factor had a positive effect on both survival of just-emerged seedlings $\left(s_{0}\right)$ during the germination period (fall and winter) and seedling survival $\left(s_{l}\right)$ during the summer and fall periods, which is consistent with several studies showing a positive impact of the frequency of wet days (Riba et al., 2002; Shriver, 2016). Both temperature and precipitation effects may be explained by the fact that recurrent warm and dry days can induce a seasonal water deficit, which may negatively impact the whole life-cycle (Manders and Smith, 1992; Peñuelas et al., 2004; Ruffault et al., 2014). Species growing in rocky habitats, such as $C$. corymbosa, are likely to be the most affected, since these soils have a very low water capacity (Ruiz-Sinoga et al., 2012; Silva et al., 2015). Moreover, herbaceous species such as $C$. corymbosa do not have a deep root system ensuring access to water over dry periods in such rocky habitats.

\subsection{Predictions from climate scenarios}

Both demographic and environmental stochasticity are important factors in determining the viability of species with small population sizes (Caswell, 2001; Crone et al., 2013; García et al., 2002). We here showed that climate variation explained a large amount of variation in vital rates and growth rates in $C$. corymbosa. We thus used stochastic models to predict the fate of $C$. corymbosa populations with both environmental stochasticity arising from climate change and demographic stochasticity. We did not include density-dependence in our model, which could make quantitative predictions overly pessimistic (Dahlgren et al., 2016). Population viability analyses are acknowledged to be relevant tools to quantitatively compare the impact of different scenarios rather than quantitatively predict the future status of populations (Coulson et al., 2001). We thus used population viability analyses to compare how the warm and the dry scenarios impacted population viability of $C$. corymbosa rather than attempting to explicitly predict future population size.

Stochastic projections predicted population declines $\left(\lambda_{\mathrm{s}}<1\right)$ under no climate change. Populations were predicted to decline even faster in the future in response to an increased frequency of extreme years in both the warm and dry scenarios. Such results are consistent with the GLMs 
showing negative impacts of warming and drought, and several studies investigating population viability in response to climate change (Andrello et al., 2012; Lawson et al., 2015; Marrero-Gómez et al., 2007; Shryock et al., 2014). More importantly, the warm scenario had more severe consequences on population viability than the dry scenario whatever the initial population size. However in our simulations, the initial population size impacted both extinction probability and the mean time to extinction, a pattern consistent with theoretical studies since small populations are more vulnerable to extinction than largest ones (Groom et al., 2005; Lande et al., 2003). Using the RCP4.5 scenario, the change in temperature projected for the period 2071-2099 was of the same order of magnitude than the one predicted by other regional climatic models (Christensen et al., 2007; Ruffault et al., 2014). In contrast, our dry scenario predicted an annual mean number of wet days equal to $66.41(-3.2 \%)$, while other models predicted a much severe decrease $(-19.6 \%$, Ruffault et al., 2014). This suggests that uncertainty in climate models should be carefully considered in management plans and when evaluating extinction risk. Such uncertainty is particularly pronounced for the Mediterranean region (Gao et al., 2008; Ruffault et al., 2014).

Faced with climate change, populations can either migrate or adapt by microevolution or phenotypic plasticity to avoid extinction (Groom et al., 2005; Lande et al., 2003). In the Mediterranean region, many narrow endemic species are characterized by a low ability to colonize existing suitable habitats due to several biological traits such as low dispersal ability (Colas et al. 1997; Lavergne et al., 2004; Thompson et al. 2005). In C. corymbosa, self-incompatibility and monocarpy make successful colonization even less likely (Colas et al., 1997). Thus, for such species, persistence mainly depends upon their ability to respond plastically to climate change or to become locally adapted to new environmental conditions (Cotto et al., 2017; Knight et al. 2008; Menges, 2000). Theoretical work suggests that perennial species should display slower evolutionary responses than annual plants, since higher adult survival limits the adaptive capacity of local populations (Cotto et al., 2017). Moreover, small populations have a lower evolutionary potential, since they become genetically impoverished due to the impact of genetic drift. Using a shorter survey (1995-2001), Fréville et al. (2001) showed that demographic rates were not correlated with intra-population genetic diversity in Centaurea corymbosa (Fréville et al., 2001). Using the same genetic data (Table 1 in Fréville et al., 2001), we likewise confirmed that genetic diversity was correlated with neither $\lambda_{\mathrm{s}}$ (Spearman correlation $\left.r h o=0.26, \mathrm{p}=0.61\right)$ nor the slope of regression in asymptotic growth rates over years $(r h o=0.09, \mathrm{p}=0.89)$. Thus, our results do not support evidence for accumulation of deleterious mutations (Lynch et al., 1995), nor a loss of standing variation due to genetic drift in small populations of C. corymbosa. 
Persistence of narrow endemic species in the Mediterranean region may have been favored by the capacity of those species to grow in rocky habitats (Thompson et al., 2005), since these remote habitats do not face direct threats due to human activities. Demographic studies of cliffdwelling species have shown unusual demographic stability and resilience of these plants (García, 2003; Lavergne et al., 2005; Picó and Riba, 2002; Thompson et al., 2005), likely arising from much higher importance of rosette survival than recruitment for the maintenance of populations (Cotto et al., 2017; Larson et al., 2000; Silva et al., 2015). In a scenario of no climate change, rosette survival (that had the highest elasticity on growth rates) should be increased from 0.71 to 0.92 to ensure the persistence of C. corymbosa in a deterministic model (Appendix G). However, management actions aimed at increasing specific vital rates, such as watering plants are not feasible in such rocky habitats. Implementing management actions that reduce the negative effects of demographic, genetic and environmental stochasticity by manipulating population size and population number appear much more promising.

Previous studies have shown the importance of biological features such as selfincompatibility and low dispersal ability on the population persistence of C. corymbosa (Colas et al. 1997). Two new populations were introduced in 1994 on the top of unoccupied cliffs thus confirming the existence of suitable but empty habitats nearby existing natural populations (Colas et al., 2008; Kirchner et al., 2006). Introduced populations exhibited on average higher plant survival than natural populations, mainly because seeds had been introduced manually in a priori suitable microsites (Colas et al. 2008). However, fecundity in introduced populations was lower than in natural ones, likely as a consequence of low local density of flowering plants, leading to strong pollen limitation (Colas et al. 2008). One introduced population has been extinct for 5 years, while the other population only harbored 35 plants in the last census performed in December 2017. In the future, protocols should be carefully designed to ensure successful introductions. For instance, introducing a large number of seeds $(>1000)$ distributed over a few sites and at yearly intervals should allow population persistence on the short term (Colas et al., 2008; Kirchner et al., 2006).

Faced with accelerated climate change, conservation policies for endangered species, such as $C$. corymbosa, should be reconsidered. As our study demonstrated the importance of climate on the fate of populations, introductions in distant habitats should be considered, although such assisted colonization event requires suitable and available habitats at a larger scale. At present, prioritization actions of conservation rely on the climatic niche of the species (Jones et al., 2016; 
549 Oliver et al., 2016), and depend on our ability to define new protected areas in Northern localities 550 (Araújo et al., 2011; Bellard et al., 2012) or microrefugia (i.e. location with a low impact of climate 551 change, Jones et al., 2016; Ulrey et al. 2016). Recently, an increasing amount of empirical evidence 552 has been gathered to document that organisms, including plants, can show microevolutionary 553 responses in natural populations (Franks et al., 2014; Thomann et al., 2013), suggesting plants can 554 adapt to new environmental conditions (Thompson et al., 2005). Therefore, reinforcement, which 555 allows increasing population size and thus reducing extinction risk arising mainly from 556 demographic and genetic stochasticity, is also potentially an efficient and reasonable management $557 \quad$ strategy for species facing climate change.

558

559

560

561

562

563

564

565

566

567

568

569

\section{Acknowledgments}

This work is part of the 'Centaurea corymbosa project' initiated by I. Olivieri, B. Colas and M. Riba in 1994. We are indebted to the many contributors to this project, and in particular to B. Colas and M. Riba who provided constructive comments on the manuscript. We would like to thank A. Duncan for English corrections, as well as the editor-in-chief V. Devictor and three anynomous reviewers for their helpful suggestions. We also thank the INRA Pech Rouge for providing us the climatic data and F. Mouillot for his advice on climate predictions. This research was supported by a fellowship from the Algerian Ministry of Higher Education (Ph-D grant to A H-B), and by the OSU-OREME.

\section{Bibliography}

AllEnvi (2016). The Mediterranean region under climate change (Paris: IRD Editions).

Andrello, M., Bizoux, J.-P., Barbet-Massin, M., Gaudeul, M., Nicole, F., and Till-Bottraud, I. (2012). Effects of management regimes and extreme climatic events on plant population viability in Eryngium alpinum. Biol. Cons. 147, 99-106.

Andrieu, E., Besnard, A., Fréville, H., Vaudey, V., Gauthier, P., Thompson, J.D., and Debussche, M. (2017). Population dynamics of Paeonia officinalis in relation to forest closure: From model predictions to practical conservation management. Biol. Cons 215, 51-60. 
Aragón-Gastélum, J.L., Badano, E., Yáñez-Espinosa, L., Ramírez-Tobías, H.M., Rodas-Ortiz, J.P., González-Salvatierra, C., and Flores, J. (2017). Seedling survival of three endemic and threatened Mexican cacti under induced climate change. Plant Species Biol. 32, 92-99.

Araújo, M.B., Alagador, D., Cabeza, M., Nogués-Bravo, D., and Thuiller, W. (2011). Climate change threatens European conservation areas. Ecol. Lett. 14, 484-492.

Bellard, C., Bertelsmeier, C., Leadley, P., Thuiller, W., and Courchamp, F. (2012). Impacts of climate change on the future of biodiversity. Ecol. Lett. 15, 365-377.

Blume-Werry, G., Kreyling, J., Laudon, H., and Milbau, A. (2016). Short-term climate change manipulation effects do not scale up to long-term legacies: effects of an absent snow cover on boreal forest plants. J. Ecol. 104, 1638-1648.

Breda, N., Huc, R., Granier, A., and Dreyer, E. (2006). Temperate forest trees and stands under severe drought: a review of ecophysiological responses, adaptation processes and long-term consequences. Ann. For. Sci. 63, 625-644.

Bucharová, A., Brabec, J., and Münzbergová, Z. (2012). Effect of land use and climate change on the future fate of populations of an endemic species in central Europe. Biol. Conserv. 145, 39-47.

Caswell, H. (2000). Prospective and retrospective perturbation analyses: their roles in conservation biology. Ecology 81, 619-627.

Caswell, H. (2001). Matrix population models: Construction, analysis, and interpretation (Sunderland, Mass: Sinauer Associates Inc.,U.S.).

Christensen, J.H., Hewitson, B., Busuioc, A., Chen, A., Gao, X., Held, R., Jones, R., Kolli, R.K., Kwon, W.K., Laprise, R., et al. (2007). Regional climate projections. In Climate Change, 2007: The Physical Science Basis. Contribution of Working Group I to the Fourth Assessment Report of the Intergovernmental Panel on Climate Change, University Press, Cambridge, (Cambridge University Press), pp. 848-940.

Christensen, L., Coughenour, M.B., Ellis, J.E., and Chen, Z.Z. (2004). Vulnerability of the Asian typical steppe to grazing and climate change. Clim. Change 63, 351-368. 
Colas, B., Riba, M., and Molina, J. (1996). Statut démographique de Centaurea corymbosa Pourret (Asteraceae), Hormatophylla pyrenaica (Lapeyr.) Cullen \& Dudley (Brassicaceae) et Marsilea strigosa Willd. (Marsileaceae-Pteridophyta), trois plantes rares du sud de la France. Acta Bot. Gallica 143, 191-198.

Colas, B., Olivieri, I., and Riba, M. (1997). Centaurea corymbosa, a cliff-dwelling species tottering on the brink of extinction: A demographic and genetic study. Proc. Natl. Acad. Sci. 94, 3471-3476.

Colas, B., Olivieri, I., and Riba, M. (2001). Spatio-temporal variation of reproductive success and conservation of the narrow-endemic Centaurea corymbosa (Asteraceae). Biol. Cons. 99, 375-386.

Colas, B., Kirchner, F., Riba, M., Olivieri, I., Mignot, A., Imbert, E., Beltrame, C., Carbonell, D., and Fréville, H. (2008). Restoration demography: a 10-year demographic comparison between introduced and natural populations of endemic Centaurea corymbosa (Asteraceae). J. Appl. Ecol. $45,1468-1476$.

Compagnoni, A., Bibian, A.J., Ochocki, B.M., Rogers, H.S., Schultz, E.L., Sneck, M.E., Elderd, B.D., Iler, A.M., Inouye, D.W., Jacquemyn, H., et al. (2016). The effect of demographic correlations on the stochastic population dynamics of perennial plants. Ecol. Monogr. 86, 480-494.

Cotto, O., Wessely, J., Georges, D., Klonner, G., Schmid, M., Dullinger, S., Thuiller, W., and Guillaume, F. (2017). A dynamic eco-evolutionary model predicts slow response of alpine plants to climate warming. Nat. Commun. 8 .

Coulson, T., Mace, G.M., Hudson, E., and Possingham, H.P. (2001). The use and abuse of population viability analysis. Trends Ecol. Evol. 16, 219-221.

Crawley, M.J. (2012). The R book (John Wiley \& Sons).

Crone, E.E., Menges, E.S., Ellis, M.M., Bell, T., Bierzychudek, P., Ehrlén, J., Kaye, T.N., Knight, T.M., Lesica, P., Morris, W.F., et al. (2011). How do plant ecologists use matrix population models? Ecol. Lett. 14, 1-8.

Crone, E.E., Ellis, M.M., Morris, W.F., Stanley, A., Bell, T., Bierzychudek, P., Ehrlen, J., Kaye, T.N., Knight, T.M., Lesica, P., et al. (2013). Ability of matrix models to explain the past and predict the future of plant populations. Cons. Biol. 27, 968-978. 
Csergő, A.M., Salguero-Gómez, R., Broennimann, O., Coutts, S.R., Guisan, A., Angert, A.L., Welk, E., Stott, I., Enquist, B.J., McGill, B., et al. (2017). Less favourable climates constrain demographic strategies in plants. Ecol. Lett. 20, 969-980.

Davison, R., Jacquemyn, H., Adriaens, D., Honnay, O., De Kroon, H., and Tuljapurkar, S. (2010). Demographic effects of extreme weather events on a short-lived calcareous grassland species: stochastic life table response experiments. J. Ecol. 98, 255-267.

Doak, D.F., and Morris, W.F. (2010). Demographic compensation and tipping points in climateinduced range shifts. Nature 467, 959-962.

Ducrocq, V. (2016). Climate change in the Mediterranean region. In The Mediterranean Region under Climate Change, (Paris: IRD Editions), p. 71.

Eckhart, V.M., Geber, M.A., Morris, W.F., Fabio, E.S., Tiffin, P., and Moeller, D.A. (2011). The geography of demography: Long-term demographic studies and species distribution models reveal a species border limited by adaptation. Am. Nat. 178, S26-S43.

Ehrlén, J., Morris, W.F., von Euler, T., and Dahlgren, J.P. (2016). Advancing environmentally explicit structured population models of plants. J. Ecol. 104, 292-305.

Engen, S., Bakke, Ø., and Islam, A. (1998). Demographic and Environmental StochasticityConcepts and Definitions. Biometrics 54, 840-846.

Engen, S., Lande, R., Sæther, B.-E., and Weimerskirch, H. (2005). Extinction in relation to demographic and environmental stochasticity in age-structured models. Math. Bio 195, 210-227.

Fant, J.B., Kramer, A., Sirkin, E., and Havens, K. (2013). Genetics of reintroduced populations of the narrowly endemic thistle, Cirsium pitcheri (Asteraceae). Botany 91, 301-308.

Fieberg, J., and Ellner, S.P. (2001). Stochastic matrix models for conservation and management: a comparative review of methods. Ecol. Lett. 4, 244-266.

Franklin, J., Serra-Diaz, J.M., Syphard, A.D., and Regan, H.M. (2017). Big data for forecasting the impacts of global change on plant communities. Glob. Ecol. Biogeogr. 26, 6-17.

Franks, S.J., Weber, J.J., and Aitken, S.N. (2014). Evolutionary and plastic responses to climate change in terrestrial plant populations. Evol. Appl. 7, 123-139. 
Fréville, H., Colas, B., Ronfort, J., Riba, M., and Olivieri, I. (1998). Predicting endemism from population structure of a widespread species: case study in Centaurea maculosa Lam. (Asteraceae). Conserv. Biol. 12, 1269-1278.

Fréville, H., Justy, F., and Olivieri, I. (2001). Comparative allozyme and microsatellite population structure in a narrow endemic plant species, Centaurea corymbosa Pourret (Asteraceae). Mol. Ecol. $10,879-889$.

Fréville, H., Colas, B., Riba, M., Caswell, H., Mignot, A., Imbert, E., and Olivieri, I. (2004). Spatial and temporal demographic variability in the endemic plant species Centaurea corymbosa (Asteraceae). Ecology 85, 694-703.

Fujiwara, M., and Caswell, H. (2001). Demography of the endangered North Atlantic right whale. Nature 414, 537-541.

Gao X., and Giorgi, F. (2008). Increased aridity in the Mediterranean region under greenhouse gas forcing estimated from high resolution simulations with a regional climate model. Glob. Plan. Change 62: 195-209.

García, M.B. (2003). Demographic viability of a relict population of the critically endangered plant Borderea chouardii. Conserv. Biol. 17, 1672-1680.

García, M.B., Guzmán, D., and Goñi, D. (2002). An evaluation of the status of five threatened plant species in the Pyrenees. Biol. Conserv. 103, 151-161.

Groom, M.J., Meffe, G.K., and Carroll, C.R. (2005). Principles of conservation biology (Sinauer Associates, Inc.).

Hardy, O.J., González-Martínez, S.C., Colas, B., Fréville, H., Mignot, A., and Olivieri, I. (2004). Fine-scale genetic structure and gene dispersal in Centaurea corymbosa (Asteraceae). II. Correlated paternity within and among sibships. Genetics 168, 1601-1614.

Heller, N.E., and Zavaleta, E.S. (2009). Biodiversity management in the face of climate change: A review of 22 years of recommendations. Biol. Conserv. 142, 14-32.

Hens, H., Pakanen, V.-M., Jäkäläniemi, A., Tuomi, J., and Kvist, L. (2017). Low population viability in small endangered orchid populations: Genetic variation, seedling recruitment and stochasticity. Biol. Cons. 210, 174-183. 
Huelber, K., Wessely, J., Gattringer, A., Moser, D., Kuttner, M., Essl, F., Leitner, M., Winkler, M., Ertl, S., Willner, W., et al. (2016). Uncertainty in predicting range dynamics of endemic alpine plants under climate warming. Glob. Change Biol. 22, 2608-2619.

Hunter, C.M., Caswell, H., Runge, M.C., Regehr, E.V., Amstrup, S.C., and Stirling, I. (2010). Climate change threatens polar bear populations: a stochastic demographic analysis. Ecology 91, 2883-2897.

Imbert, E. (2006). Dispersal by ants in Centaurea corymbosa (Asteraceae): What is the elaiosome for? P. Spec. Biol. 21, 109-117.

Imbert, E., Youssef, S., Carbonell, D., and Baumel, A. (2012). Do endemic species always have a low competitive ability? A test for two Mediterranean plant species under controlled conditions. J. P. Ecol. 5, 305-312.

IPCC (2007). Climate Change 2007 - The physical science basis: Working group I contribution to the fourth assessment report of the intergovernmental panel on climate change (United Kingdom and New York, NY, USA: Cambridge University Press).

Isik, K. (2011). Rare and endemic species: why are they prone to extinction? Turk. J. Bot. 35, 411417.

Jacob, D., Petersen, J., Eggert, B., Alias, A., Christensen, O.B., Bouwer, L.M., Braun, A., Colette, A., Deque, M., Georgievski, G., et al. (2014). EURO-CORDEX: new high-resolution climate change projections for European impact research. Reg. Environ. Change 14, 563-578.

Jeppsson, T., and Forslund, P. (2012). Can Life History Predict the Effect of Demographic Stochasticity on Extinction Risk? Am. Nat. 179, 706-720.

Jolls, C.L., Marik, J.E., Hamzé, S.I., and Havens, K. (2015). Population viability analysis and the effects of light availability and litter on populations of Cirsium pitcheri, a rare, monocarpic perennial of Great Lakes shorelines. Biol. Cons. 187, 82-90.

Kaye, T.N., and Pyke, D.A. (2003). The effect of stochastic technique on estimates of population viability from transition matrix models. Ecol. 84, 1464-1476. 
Kirchner, F., Luijten, S.H., Imbert, E., Riba, M., Mayol, M., González-Martínez, S.C., Mignot, A., and Colas, B. (2005). Effects of local density on insect visitation and fertilization success in the narrow-endemic Centaurea corymbosa (Asteraceae). Oikos 111, 130-142.

Kirchner, F., Robert, A., and Colas, B. (2006). Modelling the dynamics of introduced populations in the narrow-endemic Centaurea corymbosa: a demo-genetic integration. J. Appl. Ecol. 43, 10111021.

Kiviniemi, K., and Löfgren, A. (2009). Spatial (a) synchrony in population fluctuations of five plant species in fragmented habitats. Bas. Appl. Ecol. 10, 70-78.

Lande, R. (1993). Risks of Population Extinction from Demographic and Environmental Stochasticity and Random Catastrophes. Amer. Nat. 142, 911-927.

Lande, R., Engen, S., and Saether, B.-E. (2003). Stochastic population dynamics in ecology and conservation (Oxford; New York: Oxford University Press).

Larson, D.W., Matthes, U., Gerrath, J.A., Larson, N.W.K., Gerrath, J.M., Nekola, J.C., Walker, G.L., Porembski, S., and Charlton, A. (2000). Evidence for the widespread occurrence of ancient forests on cliffs. J. Biogeogr. 27, 319-331.

Lavergne, S., Thompson, J.D., Garnier, E., and Debussche, M. (2004). The biology and ecology of narrow endemic and widespread plants: a comparative study of trait variation in 20 congeneric pairs. Oikos 107, 505-518.

Lavergne, S., Thuiller, W., Molina, J., and Debussche, M. (2005). Environmental and human factors influencing rare plant local occurrence, extinction and persistence: a 115-year study in the Mediterranean region. J. Biogeogr. 32, 799-811.

Lawson, C.R., Vindenes, Y., Bailey, L., and van de Pol, M. (2015). Environmental variation and population responses to global change. Ecol. Lett. 18, 724-736.

Lennartsson, T., and Oostermeijer, J.G.B. (2001). Demographic variation and population viability in Gentianella campestris: effects of grassland management and environmental stochasticity. J. Ecol. $89,451-463$. 
Lynch, M., Conery, J., and Burger, R. (1995). Mutation Accumulation and the Extinction of Small Populations. Am. Nat. 146, 489-518.

Malcolm, J.R., Liu, C.R., Neilson, R.P., Hansen, L., and Hannah, L. (2006). Global warming and extinctions of endemic species from biodiversity hotspots. Cons. Biol. 20, 538-548.

Manders, P.T., and Smith, R.E. (1992). Effects of watering regime on growth and competitive ability of nursery-grown Cape fynbos and forest plants. South Afr. J. Bot. 58, 188-194.

Marrero-Gómez, M.V., Oostermeijer, J.G.B., Carqué-Álamo, E., and Bañares-Baudet, Á. (2007). Population viability of the narrow endemic Helianthemum juliae (Cistaceae) in relation to climate variability. Biol. Cons. 136, 552-562.

Matesanz, S., Escudero, A., and Valladares, F. (2009). Impact of three global change drivers on a Mediterranean shrub. Ecology 90, 2609-2621.

McDowell, N., Pockman, W.T., Allen, C.D., Breshears, D.D., Cobb, N., Kolb, T., Plaut, J., Sperry, J., West, A., Williams, D.G., et al. (2008). Mechanisms of plant survival and mortality during drought: why do some plants survive while others succumb to drought? New Phyt. 178, 719-739.

Meer, S. van der, Jacquemyn, H., Carey, P.D., and Jongejans, E. (2016). Recent range expansion of a terrestrial orchid corresponds with climate-driven variation in its population dynamics. Oecologia $181,435-448$.

Meisner, M.H., Harmon, J.P., and Ives, A.R. (2014). Temperature effects on long-term population dynamics in a parasitoid-host system. Ecol. Monogr. 84, 457-476.

Melbourne, B.A., and Hastings, A. (2008). Extinction risk depends strongly on factors contributing to stochasticity. Nature $454,100-103$.

Menges, E. (2008). TURNER REVIEW No. 16. Restoration demography and genetics of plants: when is a translocation successful? Aust. J. Bot. -56 .

Menges, E.S. (2000). Population viability analyses in plants: challenges and opportunities. Trends Ecol. Evol. 15, 51-56.

Metcalf, J.C., Rose, K.E., and Rees, M. (2003). Evolutionary demography of monocarpic perennials. Tren. Ecol. Evol. 18, 471-480. 
Morris, W.F., Pfister, C.A., Tuljapurkar, S., Haridas, C.V., Boggs, C.L., Boyce, M.S., Bruna, E.M., Church, D.R., Coulson, T., Doak, D.F., et al. (2008). Longevity can buffer plant and animal populations against changing climatic variability. Ecology 89, 19-25.

Morris, W.F., and Doak, D.F. (2002). Quantitative Conservation Biology: Theory and Practice of Population Viability Analysis (Sunderland, Mass: OUP USA).

Nakagawa, S., and Schielzeth, H. (2013). A general and simple method for obtaining R2 from generalized linear mixed-effects models. Meth. Ecol. Evol. 4, 133-142.

Nicolè, F., Dahlgren, J.P., Vivat, A., Till-Bottraud, I., and Ehrlén, J. (2011). Interdependent effects of habitat quality and climate on population growth of an endangered plant. J. Ecol. 99, 1211-1218.

Noel, F., Maurice, S., Mignot, A., Glemin, S., Carbonell, D., Justy, F., Guyot, I., Olivieri, I., and Petit, C. (2010). Interaction of climate, demography and genetics: a ten-year study of Brassica insularis, a narrow endemic Mediterranean species. Cons. Genet. 11, 509-526.

Olivieri, I., Tonnabel, J., Ronce, O., and Mignot, A. (2016). Why evolution matters for species conservation: perspectives from three case studies of plant metapopulations. Evol. Appl. 9, 196-211.

Peñuelas, J., Gordon, C., Llorens, L., Nielsen, T., Tietema, A., Beier, C., Bruna, P., Emmett, B., Estiarte, M., and Gorissen, A. (2004). Nonintrusive field experiments show different plant responses to warming and drought among sites, seasons, and species in a north-south european gradient. Ecosystems 7, 598-612.

Ramula, S., Puhakainen, L., Suhonen, J., and Vallius, E. (2008). Management actions are required to improve the viability of the rare grassland herb Carlina biebersteinii. Nor. J. Bot. 26, 83-90.

Picó, F.X., and Riba, M. (2002). Regional-scale demography of Ramonda myconi: Remnant population dynamics in a preglacial relict species. Plant Ecol. 161, 1-13.

Riba, M., Picó, F. x., and Mayol, M. (2002). Effects of regional climate and small-scale habitat quality on performance in the relict species Ramonda myconi. J. Veg. Sci. 13, 259-268.

Riba, M., Mignot, A., Fréville, H., Colas, B., Imbert, E., Vile, D., Virevaire, M., and Olivieri, I. (2005). Variation in dispersal traits in a narrow-endemic plant species, Centaurea corymbosa Pourret. (Asteraceae). Evol. Ecol. 19, 241-254. 
Ruffault, J., Martin-StPaul, N.K., Duffet, C., Goge, F., and Mouillot, F. (2014). Projecting future drought in Mediterranean forests: bias correction of climate models matters! Theor. Appl. Climatol. $117,113-122$.

Ruiz-Sinoga, J.D., Garcia-Marin, R., Gabarron-Galeote, M.A., and Martinez-Murillo, J.F. (2012). Analysis of dry periods along a pluviometric gradient in Mediterranean southern Spain. Int. J. Climatol. 32, 1558-1571.

Salguero-Gomez, R., Siewert, W., Casper, B.B., and Tielboerger, K. (2012). A demographic approach to study effects of climate change in desert plants. Philos. Trans. R. Soc. B-Biol. Sci. 367, $3100-3114$.

Selwood, K.E., McGeoch, M.A., and Mac Nally, R. (2015). The effects of climate change and landuse change on demographic rates and population viability. Biol. Rev. 90, 837-853.

Semenov, V.A., and Bengtsson, L. (2002). Secular trends in daily precipitation characteristics: greenhouse gas simulation with a coupled AOGCM. Clim. Dyn. 19, 123-140.

Shriver, R.K. (2016). Quantifying how short-term environmental variation leads to long-term demographic responses to climate change. J. Ecol. 104, 65-78.

Shryock, D.F., Esque, T.C., and Hughes, L. (2014). Population viability of pediocactus bradyi (cactaceae) in a changing climate. Am. J. Bot. 101, 1944-1953.

Silva, J.L., Mejías, J.A., and García, M.B. (2015). Demographic vulnerability in cliff-dwelling Sonchus species endemic to the western Mediterranean. Basic Appl. Ecol. 16, 316-324.

Stubben, C., and Milligan, B. (2007). Estimating and analyzing demographic models using the popbio package in R. J. Stat. Softw. 22, 1-23.

Thomann, M., Imbert, E., Devaux, C., and Cheptou, P.-O. (2013). Flowering plants under global pollinator decline. Tren. P. Sci. 18, 353-359.

Thomas, J.A., Telfer, M.G., Roy, D.B., Preston, C.D., Greenwood, J.J.D., Asher, J., Fox, R., Clarke, R.T., and Lawton, J.H. (2004). Comparative losses of British butterflies, birds, and plants and the global extinction crisis. Science 303, 1879-1881. 
Thompson, J.D., Lavergne, S., Affre, L., Gaudeul, M., and Debussche, M. (2005). Ecological differentiation of Mediterranean endemic plants. Taxon 54, 967-976.

Thuiller, W., Lavorel, S., and Araújo, M.B. (2005). Niche properties and geographical extent as predictors of species sensitivity to climate change. Glob. Ecol. Biogeogr. 14, 347-357.

Treurnicht, M., Pagel, J., Esler, K.J., Schutte-Vlok, A., Nottebrock, H., Kraaij, T., Rebelo, A.G., and Schurr, F.M. (2016). Environmental drivers of demographic variation across the global geographical range of 26 plant species. J. Ecol. 104, 331-342.

Tuffa, S., and Treydte, A.C. (2017). Modeling Boran cattle populations under climate change and varying carrying capacity. Ecol. Model. 352, 113-127.

Ulrey, C., Quintana-Ascencio, P.F., Kauffman, G., Smith, A.B., and Menges, E.S. (2016). Life at the top: Long-term demography, microclimatic refugia, and responses to climate change for a highelevation southern Appalachian endemic plant. Biol. Cons. 200, 80-92.

Whitlock, M., and Schluter, D. (2009). The analysis of biological data (Roberts and Company Publishers).

Wiens, J.J. (2016). Climate-Related Local Extinctions Are Already Widespread among Plant and Animal Species. PLOS Biol. 14, e2001104.

Williams, J.L., Jacquemyn, H., Ochocki, B.M., Brys, R., and Miller, T.E.X. (2015). Life-history evolution under climate change and its influence on the population dynamics of a long-lived plant. J. Ecol. 103, 798-808.

Yordanov, I., Velikova, V., and Tsonev, T. (2000). Plant responses to drought, acclimation, and stress tolerance. Photosynthetica 38, 171-186.

Zeigler, S. (2013). Predicting responses to climate change requires all life-history stages. J. Anim. Ecol. 82, 3-5. 


\section{Tables}

Table 1: Demographic characteristics of each of the six populations of Centaurea corymbosa, and the pooled population after pooling data across populations: number of individual life-histories recorded over 22 years (see also Appendix A1), number of surviving plants older than 1 year, mean life-time of individuals that reached the rosette stage, mean age at flowering, geometric mean of asymptotic growth rates $\left(\lambda_{a}\right)$ over 22 years, minimum and maximum of $\lambda_{a}$, stochastic growth rate $\left(\lambda_{s}\right)$ when including both demographic and environmental stochasticity (uniform frequency, see text) with the confidence intervals $\left(2.5^{\text {th }}\right.$ and $97.5^{\text {th }}$ percentiles of the simulated distributions) and the rounded mean of total numbers of flowering plants (Nb.FP) recorded by the exhaustive count over the 22 years (see appendix A2). Populations are ranked by decreasing order of total number of flowering plants.

\begin{tabular}{|c|c|c|c|c|c|c|c|c|c|}
\hline Population & $\begin{array}{c}\mathrm{Nb} . \\
\text { individuals }\end{array}$ & $\begin{array}{c}\mathrm{Nb} \text {. one } \\
\text { year plants }\end{array}$ & $\begin{array}{l}\text { Mean longevity } \\
\text { of the rosettes } \\
\text { (years) }\end{array}$ & $\begin{array}{l}\text { Mean age at } \\
\text { flowering } \\
\text { (years) }\end{array}$ & Mean $\lambda_{a}$ & {$\left[\lambda_{a} \min , \lambda_{a} \max \right]$} & $\lambda_{s}$ & $C I\left(\lambda_{s}\right)$ & $\mathrm{Nb.FP}$ \\
\hline Pooled pop. & 6112 & 1579 & 3.5 & 5.0 & 0.880 & {$[0.432,1.815]$} & 0.881 & {$[0.877,0.889]$} & 478 \\
\hline Enferret2 & 1712 & 286 & 3.3 & 4.5 & 0.749 & {$[0.240,1.585]$} & 0.836 & {$[0.829,0.851]$} & 173 \\
\hline Enferret1 & 1165 & 324 & 3.6 & 5.1 & 0.836 & {$[0.425,2.325]$} & 0.824 & {$[0.819,0.837]$} & 147 \\
\hline Auzils & 1175 & 415 & 3.5 & 5.7 & 0.783 & {$[0.331,1.391]$} & 0.792 & {$[0.786,0.807]$} & 81 \\
\hline Portes & 1064 & 268 & 3.7 & 6.2 & 0.819 & {$[0.364,1.610]$} & 0.824 & {$[0.818,0.842]$} & 34 \\
\hline Peyral & 540 & 192 & 3.2 & 4.7 & 0.710 & {$\left[0.00^{(a)}, 1.264\right]$} & 0.804 & {$[0.799,0.827]$} & 28 \\
\hline Cruzade & 456 & 94 & 3.4 & 4.2 & 0.720 & {$\left[0.00^{(a)}, 1.444\right]$} & 0.742 & {$[0.732,0.770]$} & 13 \\
\hline
\end{tabular}


Table 2: Summary of GLMs explaining the effect of two climatic variables (averaged over three-month periods) on lower-level vital rates. Only climatic variables affecting population growth rate were included in the GLMs. From the best model explaining a given lower-level vital rate, we report the estimated coefficient $(\beta)$ and its significance $(t$-test) after scaling the climatic variables. 'ns' indicates that the variable tested was not significant in the model, based on a forward stepwise selection approach (see text and appendix E. 3 for details).

\begin{tabular}{|c|c|c|c|c|c|c|c|c|}
\hline & \multicolumn{4}{|c|}{ Daily mean temperature } & \multicolumn{4}{|c|}{ No. wet days } \\
\hline & $\begin{array}{c}\text { Summer } \\
\text { [Jun-Aug] }\end{array}$ & $\begin{array}{c}\text { Fall } \\
\text { [Sep-Nov] }\end{array}$ & $\begin{array}{c}\text { Winter } \\
{[\text { Dec-Fev] }}\end{array}$ & $\begin{array}{c}\text { Spring } \\
\text { [Mar-May] }\end{array}$ & $\begin{array}{c}\text { Summer } \\
\text { [Jun-Aug] }\end{array}$ & $\begin{array}{c}\text { Fall } \\
{[\text { Sep-Nov] }}\end{array}$ & $\begin{array}{c}\text { Winter } \\
{[\text { Dec-Fev] }}\end{array}$ & $\begin{array}{c}\text { Spring } \\
\text { [Mar-May] }\end{array}$ \\
\hline Fecundity term $\log (f+1)$ & $-0.28 * *$ & $-0.22 *$ & ns & ns & ns & ns & ns & ns \\
\hline Survival of just emerged seedling $\boldsymbol{s}_{\boldsymbol{0}}$ & $-0.17 * * *$ & $-0.08^{*}$ & ns & ns & ns & $0.24 * * *$ & $0.14 * * *$ & ns \\
\hline Seedling survival $s_{1}$ & $-0.28 * * *$ & $-0.12^{+}$ & ns & ns & $0.34 * * *$ & $0.04^{+}$ & ns & ns \\
\hline Rosette survival $s_{2}$ & $-0.45 * * *$ & ns & ns & ns & ns & ns & ns & $\mathrm{ns}$ \\
\hline Flowering probability of rosette $\alpha_{2}$ & $-0.23 * * *$ & ns & ns & ns & ns & $0.19 *$ & ns & ns \\
\hline
\end{tabular}


586

587

588

589

590

591

592

593

594

595

596

597

598

599

600

601

602

603

604

605

606

607

608

609

610

611

612

613

614

615

Figure 1: Climatic variation observed in the Massif de la Clape between 1995 and 2016. Climatic variables were calculated per pair-of-years from June $(t)$ to May $(t+1)$. The solid line represents the average daily mean temperature $\left(\mathrm{C}^{\circ}\right)$, and the dashed line represents the number of wet days. Values in the vertical bars indicate the cumulative precipitation per pair-of-years. Year on the $\mathrm{x}$-axis corresponds to June $(t)$. Data were obtained from INRA Pech Rouge.

Figure 2: Asymptotic growth rates $\left(\lambda_{a}\right)$ per pair-of-years. Panel A represents yearly $\lambda_{a}$ values (circles) with their trend over years (dashed line) calculated from 125 matrices. The solid line represents the values of $\lambda_{a}$ (triangles) pooling individuals in a single population. Panels $\mathrm{B}, \mathrm{C}$ and $\mathrm{D}$ represent the trend in $\lambda_{a}$ over years for the largest populations (E2 and E1), the medium size populations ( $\mathrm{Au}$ and $\mathrm{Po}$ ) and the smallest ones ( $\mathrm{Pe}$ and $\mathrm{Cr}$ ). $\mathrm{R}^{2}$ corresponds to the $\mathrm{r}$-squared value obtained from the linear regression and "ns" indicates that the slope was not significantly different from 0 . Year on the $\mathrm{x}$-axis corresponds to June $(\mathrm{t})$.

Figure 3: Contribution of lower-level vital rates to the variance of $\lambda_{a}$ observed among years, and elasticity of growth rates to these vital rates calculated on the arithmetic mean matrix calculated over 21 pair-of-years matrices.

Figure 4: Predicted consequences of the warm and dry scenarios on the viability of populations using two different initial population sizes representing the largest (Enferret2) and the smallest (Cruzade) populations when incorporating both demographic and environmental stochasticity (see text for details). Panels (A) and (C) represent the warm scenario for the largest population size $\left(N_{0}=\right.$ $\{685796118\}$, Enferret2), and the smallest one $\left(N_{0}=\{41477\}\right.$, Cruzade). Panels (B) and (D) represent the dry scenario for Enferret2 and Cruzade, respectively. The warm scenario consisted of an increase in the frequency of years with extremely high temperatures (4 extreme years out of 21: 2006-2007, 2013-2014, 2014-2015), and the dry scenario an increase in the frequency of years with an extremely low number of wet days (3 extreme years out of 21: 2001-2002, 2006-2007 and 20102011). ' $q$ ' indicates the frequency of extreme years with $q^{*}$ the observed frequency over the 22-year of our demographic survey and $\mathrm{q}_{\text {pred }}$ the frequency predicted by the RCP4.5 climatic model for the warm and dry scenarios ( $\mathrm{q}_{\text {pred }}$ are 0.78 and 0.15 , respectively, see text). The initial population size was estimated as the stable stage distribution predicted by the mean matrix over years after pooling data across populations, using the mean total number of flowering plants recorded from 2010 to 2016 in Enferret2 and Cruzade, respectively. 


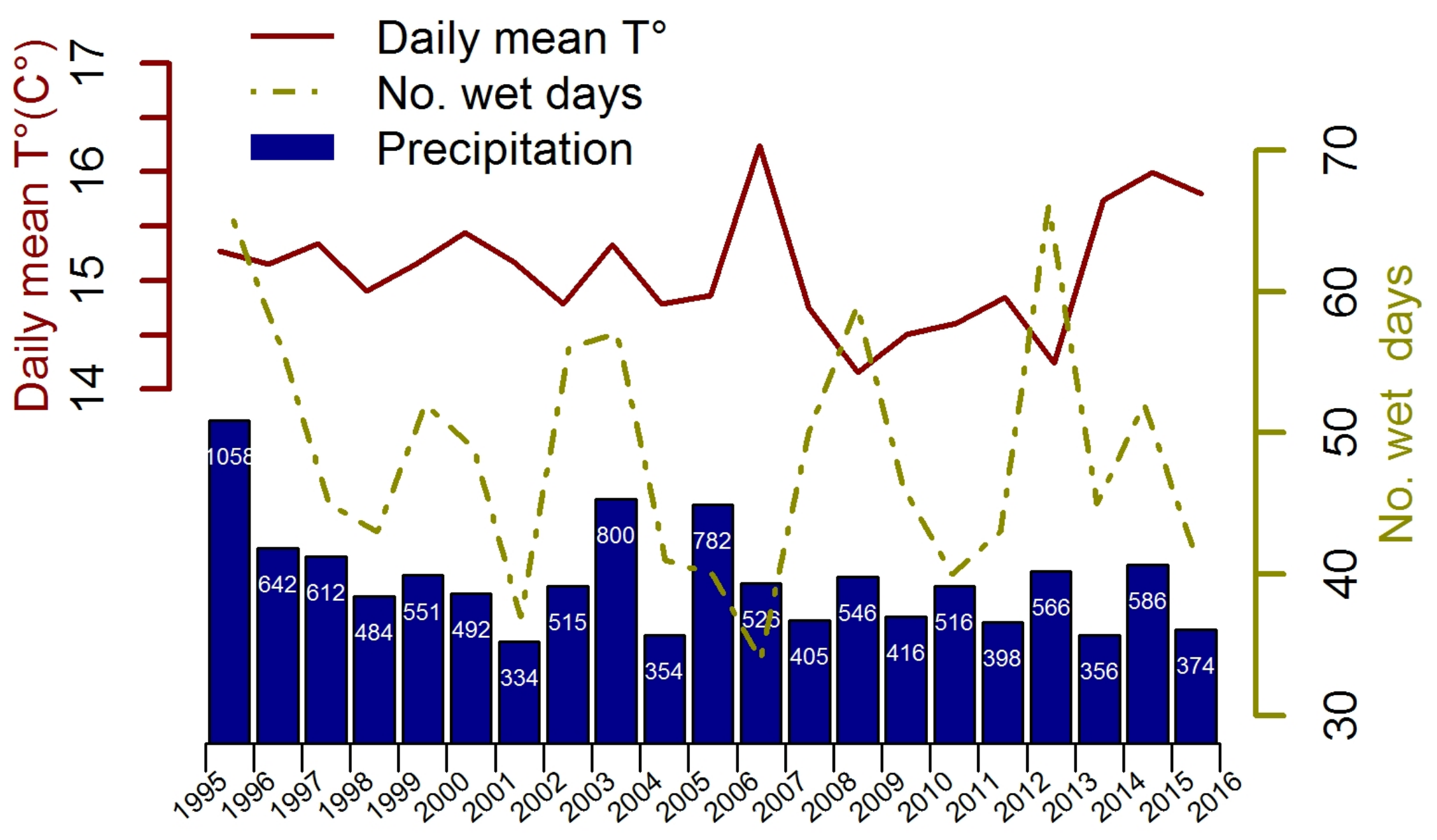



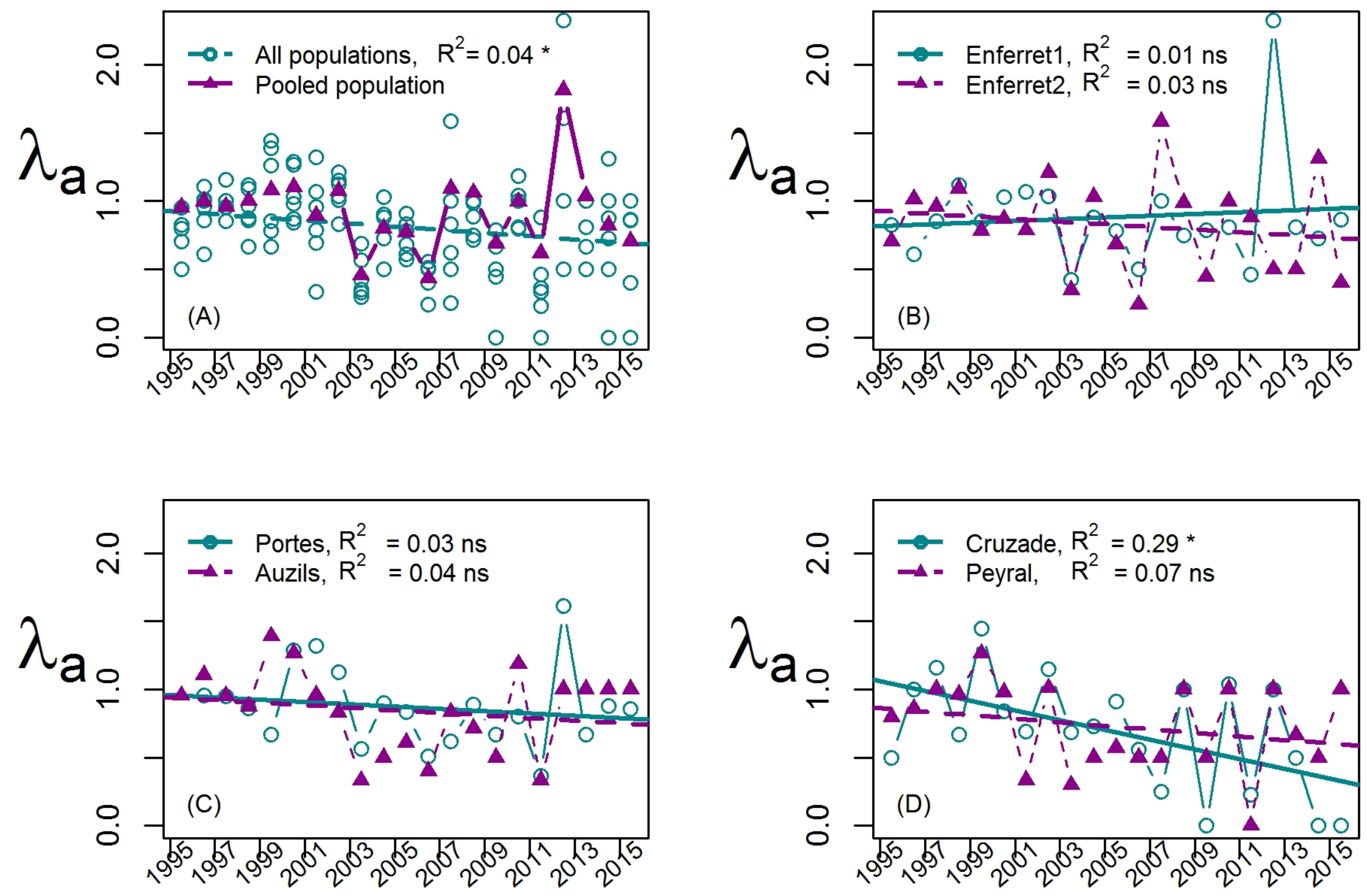

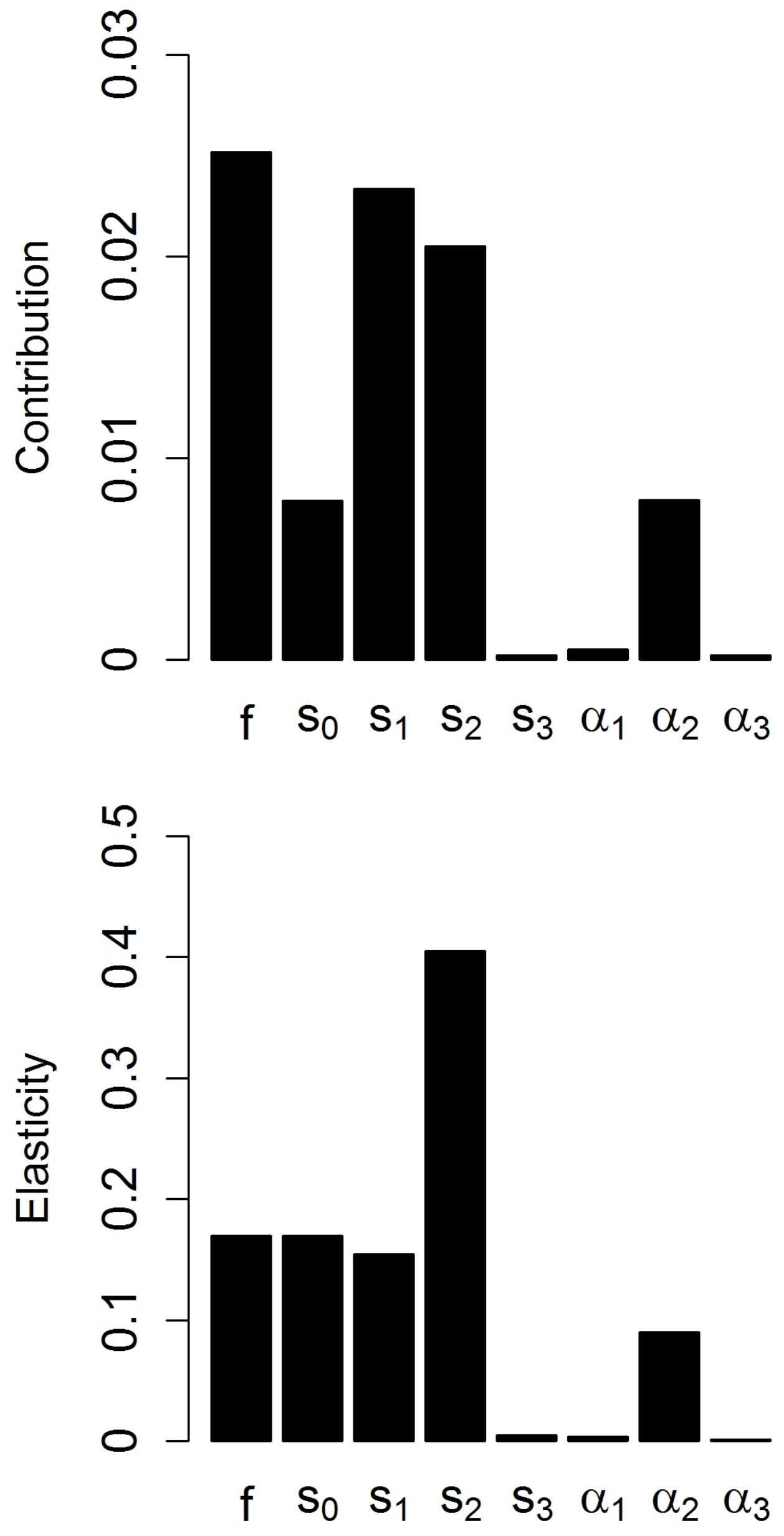


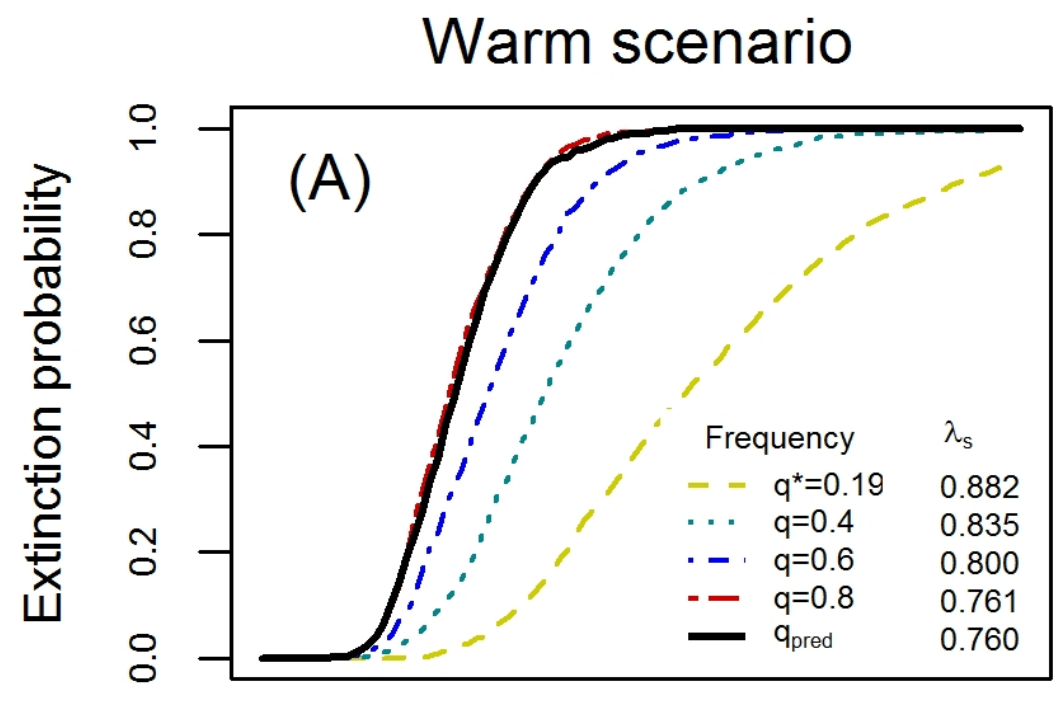

\section{Dry scenario}
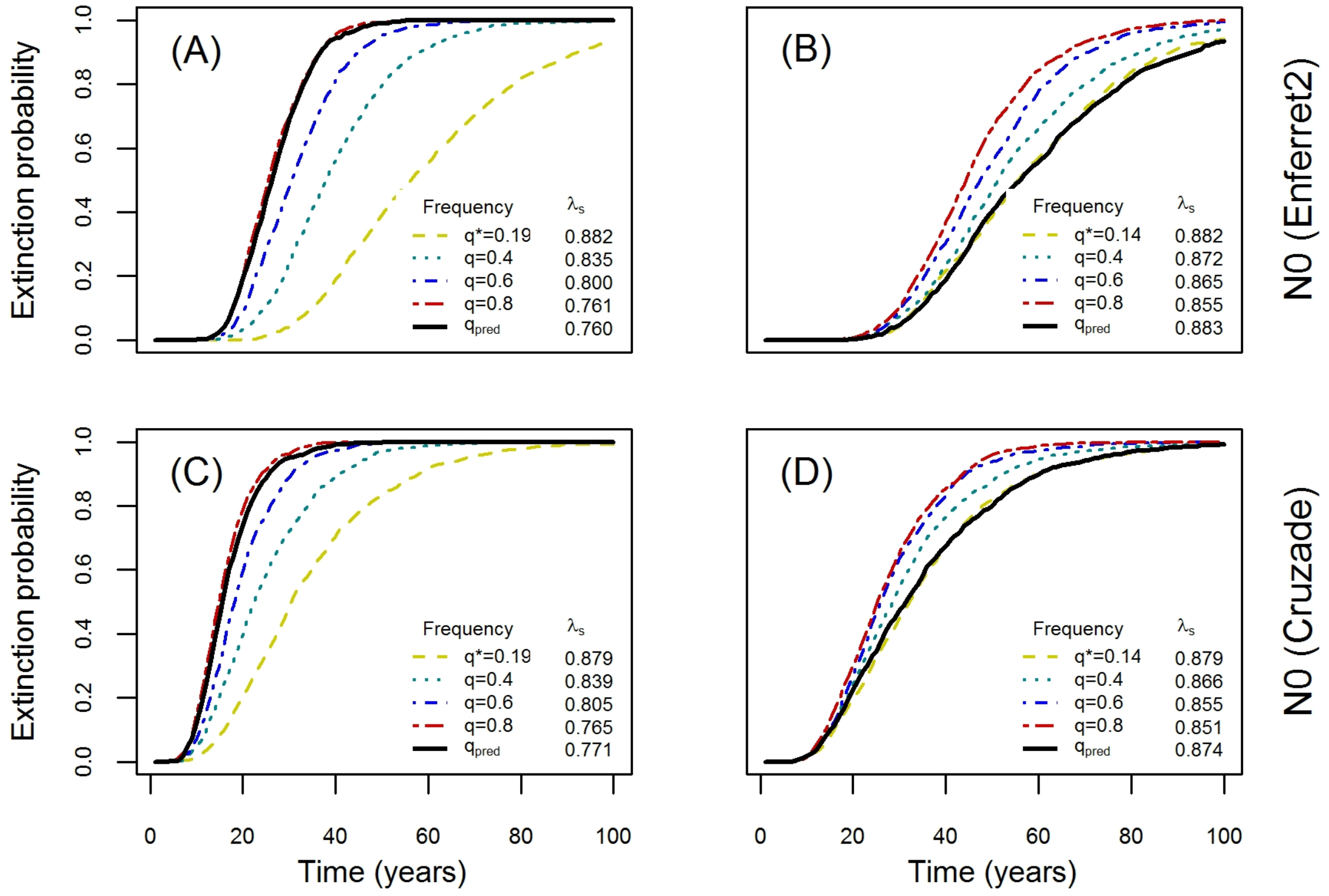


\section{Appendices:}

Appendix A1: Number of individuals recorded within the 41 permanent plots over the 22-year period. Number of new seedlings represents all new plants recorded in the permanent plots every 3 months during year $t$ to $t+1$, out of which some did not survive until June $t+1$ with a probability 1 - $\mathrm{s}_{0}$, and thus did not reach the seedling stage. The number of individuals recorded in June $(t)$ in each life-stage of the life-cycle used to construct population projection models, is given for: Seedling, the one-year plants that survive until June $(t)$, Rosette, vegetative plants older than one year, and Flowering plants that represent reproductive plants. The total number of individuals per year did not include the new seedlings. The total individual life-histories (6112) corresponds to the sum of number of new seedlings (5779) and number of rosettes and flowering plants at the first census $(315+18)$.

\begin{tabular}{cccccc}
\hline Year & New seedlings & $\begin{array}{c}\text { Seedling } \\
\text { stage }\end{array}$ & $\begin{array}{c}\text { Rosette } \\
\text { stage }\end{array}$ & $\begin{array}{c}\text { Flowering plant } \\
\text { stage }\end{array}$ & Total \\
\hline 1994 & NA & NA & 315 & 18 & 333 \\
1995 & 467 & 234 & 161 & 35 & 430 \\
1996 & 258 & 145 & 184 & 48 & 377 \\
1997 & 608 & 181 & 160 & 48 & 389 \\
\hline 1998 & 427 & 165 & 195 & 28 & 388 \\
1999 & 349 & 204 & 178 & 37 & 419 \\
\hline 2000 & 284 & 164 & 218 & 41 & 423 \\
\hline 2001 & 1097 & 475 & 204 & 30 & 709 \\
\hline 2002 & 466 & 356 & 250 & 17 & 623 \\
\hline 2003 & 167 & 115 & 357 & 30 & 502 \\
\hline 2004 & 299 & 197 & 144 & 12 & 353 \\
\hline 2005 & 73 & 45 & 137 & 17 & 199 \\
\hline 2006 & 262 & 30 & 97 & 22 & 149 \\
\hline 2007 & 72 & 42 & 40 & 9 & 91 \\
\hline 2008 & 182 & 47 & 45 & 9 & 101 \\
\hline 2009 & 368 & 102 & 43 & 6 & 151 \\
\hline 2010 & 67 & 29 & 36 & 3 & 68 \\
\hline 2011 & 29 & 15 & 44 & 3 & 62 \\
\hline 2012 & 50 & 8 & 20 & 6 & 34 \\
\hline 2013 & 116 & 93 & 19 & 7 & 119 \\
\hline 2014 & 89 & 45 & 41 & 4 & 90 \\
\hline 2015 & 31 & 10 & 48 & 5 & 46 \\
\hline 2016 & 18 & 9 & 35 & 2 & \\
\hline Total & 5779 & 2711 & 2971 & 437 & \\
\hline & & & & & \\
\hline
\end{tabular}


Appendix A2: Total number of flowering plants per year recorded by the exhaustive count per population. The dashed line corresponds to the trend of the number of flowering plants over time ( $\beta$ $=-2.21, p=0.02$ ). The growth rate calculated from the number of flowering plants was equal to 0.92 .

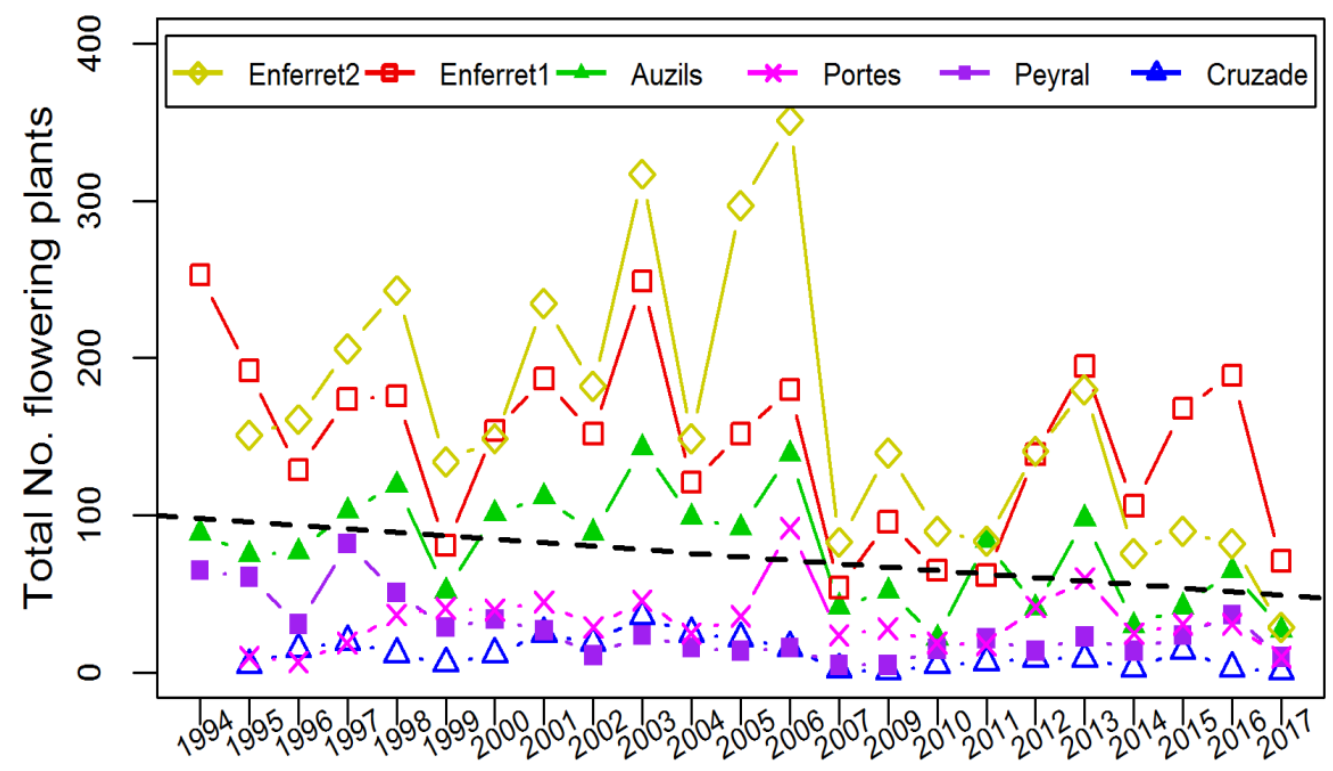

Appendix B: Projections matrices per population. The fecundity term $f_{S_{0}}$ was estimated as the geometric mean of $f s_{0}$ obtained per pair-of-years, other parameters are obtained by pooling data over years.

\begin{tabular}{cccccccc}
\hline Population & $\begin{array}{c}a_{13} \\
f_{0}\end{array}$ & $\begin{array}{c}a_{21} \\
s_{1}\left(1-\alpha_{1}\right)\end{array}$ & $\begin{array}{c}a_{22} \\
s_{2}\left(1-\alpha_{2}\right)\end{array}$ & $\begin{array}{c}a_{23} \\
s_{3}\left(1-\alpha_{3}\right)\end{array}$ & $\begin{array}{c}a_{31} \\
s_{1} \alpha_{1}\end{array}$ & $\begin{array}{c}a_{32} \\
s_{2} \alpha_{2}\end{array}$ & $\begin{array}{c}a_{33} \\
s_{3} \alpha_{3}\end{array}$ \\
\hline Pooled pop. & 5.104 & 0.351 & 0.586 & 0.024 & 0.011 & 0.120 & 0.038 \\
\hline Enferret2 & 4.267 & 0.345 & 0.509 & 0.029 & 0.029 & 0.165 & 0.029 \\
\hline Enferret1 & 3.834 & 0.347 & 0.595 & 0.000 & 0.009 & 0.119 & 0.035 \\
\hline Auzils & 4.549 & 0.379 & 0.598 & 0.026 & 0.000 & 0.094 & 0.026 \\
\hline Portes & 4.283 & 0.294 & 0.640 & 0.017 & 0.011 & 0.113 & 0.017 \\
\hline Peyral & 3.601 & 0.404 & 0.573 & 0.067 & 0.000 & 0.108 & 0.067 \\
\hline Cruzade & 2.819 & 0.361 & 0.593 & 0.020 & 0.016 & 0.174 & 0.082 \\
\hline
\end{tabular}


Appendix C: Distribution of the standard deviation of asymptotic growth rates under the null hypothesis of: (A) no difference among years and (B) no difference among populations. The $\mathrm{x}$-axis represents the standard deviation of $\lambda_{a}$ calculated (A) over the 21 year values, (B) over the 6 population values. The $y$-axis represents the number of observations. The dashed vertical lines indicate the observed value. Randomization tests were based on 2000 permutations.

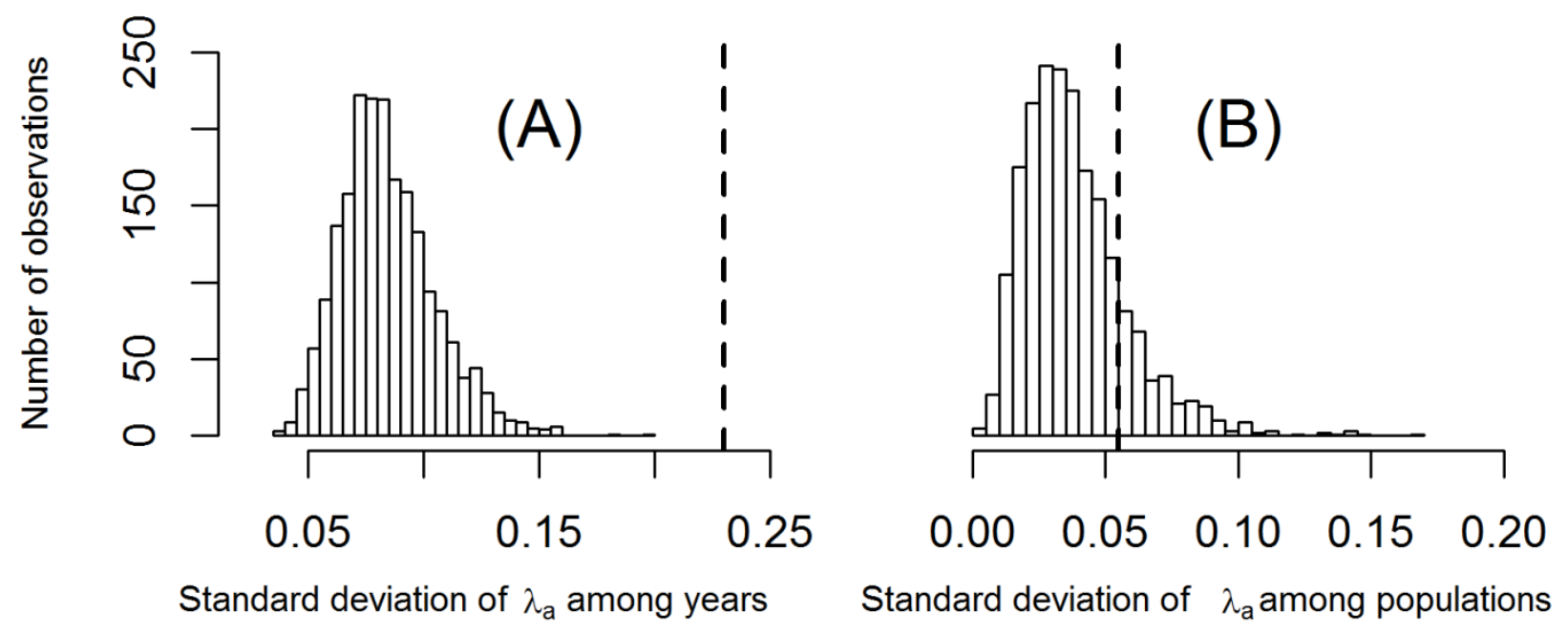

Appendix D: Arithmetic mean and coefficient of variation of lower-level vital rates over years after pooling data over populations, sensitivity and elasticity of growth rates to these vital rates calculated at the arithmetic mean matrix over 21 matrices, and contributions of lower-level vital rates to the variation of growth rates among years.

\begin{tabular}{lcccccccc}
\hline & $\mathbf{f}$ & $\mathbf{s}_{\mathbf{0}}$ & $\mathbf{s}_{\mathbf{1}}$ & $\mathbf{s}_{\mathbf{2}}$ & $\mathbf{s}_{\mathbf{3}}$ & $\boldsymbol{\alpha}_{\mathbf{1}}$ & $\boldsymbol{\alpha}_{\mathbf{2}}$ & $\boldsymbol{\alpha}_{\mathbf{3}}$ \\
\hline Mean & 13.235 & 0.484 & 0.363 & 0.732 & 0.059 & 0.016 & 0.181 & 0.217 \\
\hline CV & 0.644 & 0.395 & 0.505 & 0.184 & 1.046 & 2.598 & 0.386 & 1.352 \\
\hline Sensitivity & 0.017 & 0.457 & 0.55 & 0.721 & 0.117 & 0.31 & 0.648 & 0.008 \\
\hline Elasticity & 0.170 & 0.170 & 0.155 & 0.405 & 0.005 & 0.004 & 0.090 & 0.001 \\
\hline Contribution & 0.025 & 0.008 & 0.023 & 0.021 & $<0.001$ & $<0.001$ & 0.008 & $<0.001$ \\
\hline
\end{tabular}


Appendix E.1: Single-variable log-linear models showing the relationship between asymptotic growth rates and each climatic variable. $\mathrm{R}^{2}$ corresponds to the coefficient of determination for the tested model.

\begin{tabular}{lccl}
\hline \multicolumn{1}{c}{ Climatic variable in year $t$} & $\mathrm{R}^{2}$ & Estimate & $\mathrm{p}$-value \\
\hline${\text { Daily mean } \mathrm{T}^{\circ}}^{\circ}$ & 0.31 & -0.320 & $\mathbf{0 . 0 1 1}$ \\
\hline Daily maximal $\mathrm{T}^{\circ}$ & 0.30 & -0.250 & $\mathbf{0 . 0 0 9}$ \\
\hline Precipitation & 0.01 & -0.001 & 0.672 \\
\hline No. days with $\mathrm{T}^{\circ}>25$ & 0.18 & -0.013 & 0.052 \\
\hline No. freezing days & 0.03 & 0.008 & 0.451 \\
\hline No. wet days & 0.46 & 0.021 & $\mathbf{0 . 0 0 1}$ \\
\hline No. days with precip. $>20 \mathrm{~mm}$ & 0.04 & -0.021 & 0.381 \\
\hline \multicolumn{1}{c}{ Climatic variables in year $t-1$} & & & \\
\hline Daily mean $\mathrm{T}^{\circ}$ & 0.003 & 0.031 & 0.251 \\
\hline Daily maximal $\mathrm{T}^{\circ}$ & 0.006 & 0.032 & 0.233 \\
\hline Precipitation & 0.058 & -0.001 & 0.452 \\
\hline No. days with $\mathrm{T}^{\circ}>25$ & 0.005 & -0.002 & 0.253 \\
\hline No. freezing days & 0.001 & 0.001 & 0.360 \\
\hline No. wet days & 0.012 & -0.004 & 0.250 \\
\hline No. days with precip.>20mm & 0.010 & -0.009 & 0.141 \\
\hline \multicolumn{1}{c}{ Quadratic effect $^{\circ}$} & & & \\
\hline Daily mean $\mathrm{T}^{\circ}$ & 0.30 & -0.011 & $\mathbf{0 . 0 1 0}$ \\
\hline Daily maximal $\mathrm{T}^{\circ}$ & 0.30 & -0.006 & $\mathbf{0 . 0 0 9}$ \\
\hline Precipitation & 0.01 & 0.000 & 0.631 \\
\hline No. days with $\mathrm{T}^{\circ}>25$ & 0.18 & -0.001 & 0.052 \\
\hline No. freezing days & 0.02 & 0.000 & 0.540 \\
\hline No. days with precip.>20mm & 0.43 & 0.003 & $\mathbf{0 . 0 0 2}$ \\
\hline
\end{tabular}


Appendix E.2: Selection models for assessing the relevance of climatic variables to explain variations in asymptotic growth rates based on a forward stepwise selection approach. The significance of each added variable in the model was tested using an analysis of deviance. The null model included only the intercept.

\begin{tabular}{lcl}
\hline \multicolumn{1}{c}{ Model } & Compared models & p-value \\
\hline M0: Null model & & \\
\hline M1: No. wet days & M0, M1 & $\mathbf{0 . 0 0 1}$ \\
\hline M2: No. wet days + (No. wet days) ${ }^{2}$ & M1, M2 & 0.311 \\
\hline M3: No. wet days + Daily mean $\mathrm{T}^{\circ}$ & M1, M3 & $\mathbf{0 . 0 3 1}$ \\
\hline M4: No. wet days + Daily mean $\mathrm{T}^{\circ}+\left(\text { Daily mean } \mathrm{T}^{\circ}\right)^{2}$ & M3, M4 & 0.292 \\
\hline M5: No. wet days + Daily mean $\mathrm{T}^{\circ}+$ Daily maximal $^{\circ}$ & M3, M5 & 0.890 \\
\hline M6: No. wet days + Daily mean $\mathrm{T}^{\circ}+\left(\text { Daily maximal } \mathrm{T}^{\circ}\right)^{2}$ & $\mathrm{M} 3, \mathrm{M} 6$ & 0.843 \\
\hline
\end{tabular}


Appendix E.3: Selection models for assessing the relevance of climatic variables to explain variations in lower-level vital rates based on a forward stepwise selection approach. P-values correspond to the F-test for the log-linear models and to Chi-test for the generalized linear models with binomial error. The null model included only the intercept. We denoted the number of days with Precipitation $>1 \mathrm{~mm}$ by "P" and the mean daily temperature by "T". The seasons are denoted by 1, 2, 3 and 4 to indicate summer, fall, winter and spring, respectively (see the main text and Table 2)

\begin{tabular}{|c|c|c|c|}
\hline $\begin{array}{c}\text { Lower-level } \\
\text { vital rate }\end{array}$ & Model & $\begin{array}{c}\text { Compared } \\
\text { models }\end{array}$ & p-value \\
\hline \multirow{10}{*}{$\log (f+1)$} & M0: Null model & & \\
\hline & M1: T1 & M0, M1 & 0.012 \\
\hline & M2: T1+T2 & M1, M2 & 0.031 \\
\hline & M3: $\mathrm{T} 1+\mathrm{T} 2+\mathrm{T} 3$ & M2, M3 & 0.165 \\
\hline & $\mathrm{M} 4: \mathrm{T} 1+\mathrm{T} 2+\mathrm{T} 4$ & M2, M4 & 0.583 \\
\hline & M5: $\mathrm{T} 1+\mathrm{T} 2+\mathrm{P} 1$ & M2, M5 & 0.794 \\
\hline & M6: $\mathrm{T} 1+\mathrm{T} 2+\mathrm{P} 2$ & M2, M6 & 0.222 \\
\hline & $\mathrm{M} 7: \mathrm{T} 1+\mathrm{T} 2+\mathrm{P} 3$ & $\mathrm{M} 2, \mathrm{M} 7$ & 0.806 \\
\hline & M8: $\mathrm{T} 1+\mathrm{T} 2+\mathrm{P} 4$ & M2, M8 & 0.236 \\
\hline & \multicolumn{3}{|c|}{ Selected model: $\log (f+1) \sim \mathrm{T} 1+\mathrm{T} 2$} \\
\hline \multirow{10}{*}{$S_{0}$} & M0: Null model & & \\
\hline & M1: P2 & M0, M1 & $<0.001$ \\
\hline & $\mathrm{M} 2: \mathrm{P} 2+\mathrm{P} 3$ & $\mathrm{M} 1, \mathrm{M} 2$ & $<0.001$ \\
\hline & $\mathrm{M} 3: \mathrm{P} 2+\mathrm{P} 3+\mathrm{T} 2$ & $\mathrm{M} 2, \mathrm{M} 3$ & 0.006 \\
\hline & $\mathrm{M} 4: \mathrm{P} 2+\mathrm{P} 3+\mathrm{T} 2+\mathrm{T} 1$ & M3, M4 & $<0.001$ \\
\hline & $\mathrm{M} 5: \mathrm{P} 2+\mathrm{P} 3+\mathrm{T} 2+\mathrm{T} 1+\mathrm{P} 1$ & M4, M5 & 0.082 \\
\hline & M6: P2+P3+T2+T1+T3 & M4, M6 & 0.087 \\
\hline & $\mathrm{M} 7: \mathrm{P} 2+\mathrm{P} 3+\mathrm{T} 2+\mathrm{T} 1+\mathrm{T} 4$ & $\mathrm{M} 4, \mathrm{M} 7$ & 0.120 \\
\hline & $\mathrm{M} 8: \mathrm{P} 2+\mathrm{P} 3+\mathrm{T} 2+\mathrm{T} 1+\mathrm{P} 4$ & M4, M8 & 0.091 \\
\hline & \multicolumn{3}{|c|}{ Selected model: $S_{0} \sim \mathrm{T} 1+\mathrm{T} 2+\mathrm{P} 2+\mathrm{P} 3$} \\
\hline \multirow{5}{*}{$S_{1}$} & M0: Null model & & \\
\hline & M1: T1 & M0, M1 & $<0.001$ \\
\hline & $\mathrm{M} 2: \mathrm{T} 1+\mathrm{P} 1$ & $\mathrm{M} 1, \mathrm{M} 2$ & $<0.001$ \\
\hline & M3: $\mathrm{T} 1+\mathrm{P} 1+\mathrm{P} 2$ & M2, M3 & 0.002 \\
\hline & $\mathrm{M} 4: \mathrm{T} 1+\mathrm{P} 1+\mathrm{P} 2+\mathrm{T} 4$ & M3, M4 & 0.974 \\
\hline
\end{tabular}




\begin{tabular}{lll}
$\mathrm{M} 5: \mathrm{T} 1+\mathrm{P} 1+\mathrm{P} 2+\mathrm{P} 3$ & $\mathrm{M} 3, \mathrm{M} 5$ & 0.352 \\
\hline $\mathrm{M} 6: \mathrm{T} 1+\mathrm{P} 1+\mathrm{P} 2+\mathrm{P} 4$ & $\mathrm{M} 3, \mathrm{M} 6$ & 0.072 \\
\hline $\mathrm{M} 7: \mathrm{T} 1+\mathrm{P} 1+\mathrm{P} 2+\mathrm{T} 3$ & $\mathrm{M} 3, \mathrm{M} 7$ & 0.316 \\
\hline $\mathrm{M} 8: \mathrm{T} 1+\mathrm{P} 1+\mathrm{P} 2+\mathrm{T} 2$ & $\mathrm{M} 3, \mathrm{M} 8$ & $\mathbf{0 . 0 3 0}$
\end{tabular}

Selected model: $S_{1} \sim \mathrm{T} 1+\mathrm{T} 2+\mathrm{P} 1+\mathrm{P} 2$

M0: Null model

\begin{tabular}{lcc}
\hline M1: T1 & M0, M1 & $<\mathbf{0 . 0 0 1}$ \\
\hline M2: T1 + P1 & M1, M2 & 0.692
\end{tabular}

$\mathbf{S}_{2}$

\begin{tabular}{lcc}
\hline M3: T1+P2 & M1, M3 & 0.115 \\
\hline M4: T1+P3 & M1, M4 & 0.174 \\
\hline M5: T1+ P4 & M1, M5 & 0.092 \\
\hline M6: T1+ T2 & M1, M6 & 0.163 \\
\hline M7: T1+T3 & M1, M7 & 0.662 \\
\hline M8: T1+T4 & M1, M8 & 0.365
\end{tabular}

Selected model: $S_{2} \sim \mathrm{T} 1$

M0: Null model

\begin{tabular}{llc}
\hline $\mathrm{M} 1: \mathrm{T} 1$ & $\mathrm{M} 0, \mathrm{M} 1$ & $\mathbf{0 . 0 0 5}$ \\
\cline { 2 - 4 } $\mathrm{M} 2: \mathrm{T} 1+\mathrm{T} 4$ & $\mathrm{M} 1, \mathrm{M} 2$ & 0.122 \\
\cline { 2 - 4 } $\mathrm{M} 3: \mathrm{T} 1+\mathrm{P} 1$ & $\mathrm{M} 1, \mathrm{M} 3$ & 0.251 \\
\hline $\mathrm{M} 4: \mathrm{T} 1+\mathrm{P} 4$ & $\mathrm{M} 1, \mathrm{M} 4$ & 0.071 \\
\hline $\mathrm{M} 5: \mathrm{T} 1+\mathrm{P} 2$ & $\mathrm{M} 1, \mathrm{M} 5$ & $\mathbf{0 . 0 2 0}$ \\
\hline $\mathrm{M} 6: \mathrm{T} 1+\mathrm{P} 2+\mathrm{P} 3$ & $\mathrm{M} 5, \mathrm{M} 6$ & 0.415 \\
\hline $\mathrm{M} 7: \mathrm{T} 1+\mathrm{P} 2+\mathrm{T} 2$ & $\mathrm{M} 5, \mathrm{M} 7$ & 0.868 \\
\hline $\mathrm{M} 8: \mathrm{T} 1+\mathrm{P} 2+\mathrm{T} 3$ & $\mathrm{M} 5, \mathrm{M} 8$ & 0.976
\end{tabular}

Selected model: $\alpha_{2} \sim \mathrm{T} 1+\mathrm{P} 2$ 
Appendix F: Relative effect of demographic stochasticity and environmental stochasticity on the viability of $C$. corymbosa populations. Simulations were performed either by incorporating only environmental stochasticity through whole matrix selection (see text), or both environmental stochasticity and demographic stochasticity introduced through multinomial sampling of the stable stage distribution (see text). Projections were simulated using 1000 stochastic iterations, each iteration representing a trajectory of population size over 100 years. The initial population size, $N_{0}=$ $\{2148,2497,370\}$, used to start our simulations was calculated from the stable stage distribution obtained from the arithmetic mean of the total number of flowering plants recorded in the population (exhaustive survey, Appendix A2) from 2010 to 2016, and the scaled eigenvector $W$ from the arithmetic mean matrix over years (2010-2016) when pooling data over populations (see text for details). Extinction probability at a given time $t$ corresponds to the number of trajectories for which $N(t)<1$ over the total number of trajectories. $\mathrm{T}_{0.5}$ represents the time corresponding to an extinction probability equal to $\mathrm{P}=0.5$.

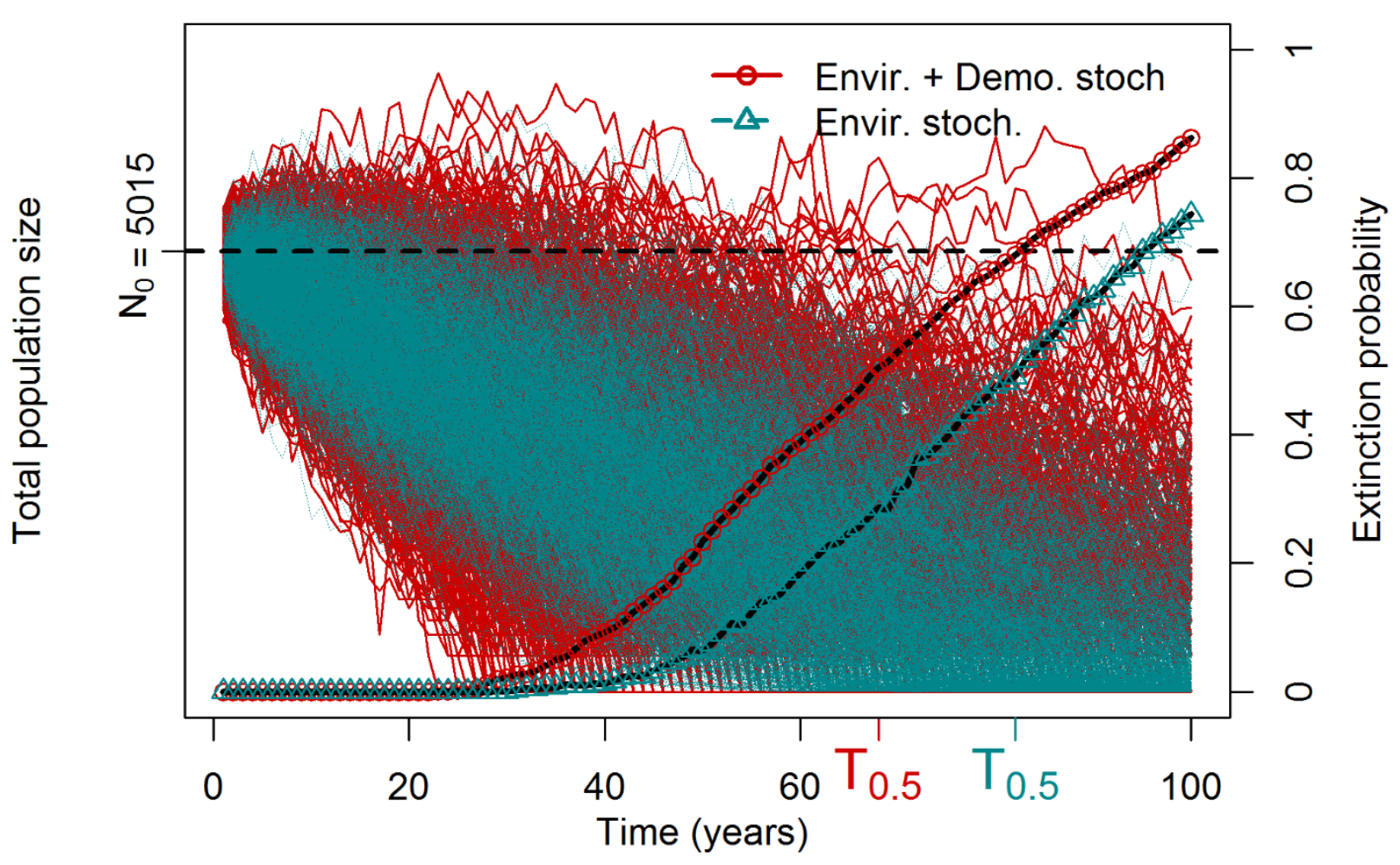


Appendix G: Required values of lower-level vital rates for achieving population persistence in a deterministic model $\left(\lambda_{\mathrm{a}}=1\right)$, using two different methods: lower-level vital rates values were either predicted from the elasticity values, or directly from the global mean matrix after pooling individuals over populations and years to obtain a single population. For both methods, we varied only one vital rate at a time, while keeping others at their observed value in the mean matrix.

\begin{tabular}{lccc}
\hline \multirow{2}{*}{ Vital rates } & Observed & \multicolumn{2}{c}{ Required value } \\
\cline { 3 - 4 } & value & $\begin{array}{c}\text { Elasticity } \\
\text { prediction }\end{array}$ & $\begin{array}{c}\text { Prediction from the } \\
\text { global matrix }\end{array}$ \\
\hline Survival of just-emerged seedling $s_{0}$ & 0.477 & 0.811 & 0.790 \\
\hline Rosette survival $s_{2}$ & 0.707 & 0.918 & 0.937 \\
\hline Fecundity term $f$ & 11.16 & 18.98 & 18.50 \\
\hline
\end{tabular}

